\title{
Flux distributions in anaerobic, glucose-limited continuous cultures of Saccharomyces cerevisiae
}

\author{
Torben L. Nissen, Ulrik Schulze, Jens Nielsen and John Villadsen
}

Author for correspondence: Torben L. Nissen. Tel: +4545252670 . Fax: +4545884148 .

Department of

Biotechnology, Technical University of Denmark, 2800 Lyngby, Denmark

\begin{abstract}
A stoichiometric model describing the anaerobic metabolism of Saccharomyces cerevisiae during growth on a defined medium was derived. The model was used to calculate intracellular fluxes based on measurements of the uptake of substrates from the medium, the secretion of products from the cells, and of the rate of biomass formation. Furthermore, measurements of the biomass composition and of the activity of key enzymes were used in the calculations. The stoichiometric network consists of 37 pathway reactions involving 43 compounds of which 13 were measured (acetate, $\mathrm{CO}_{2}$, ethanol, glucose, glycerol, $\mathrm{NH}_{4}^{+}$, pyruvate, succinate, carbohydrates, DNA, lipids, proteins and RNA). The model was used to calculate the production rates of malate and fumarate and the ethanol measurement was used to validate the model. All rate measurements were performed on glucose-limited continuous cultures in a high-performance bioreactor. Carbon balances closed within $98 \%$. The calculations comprised flux distributions at specific growth rates of 0.10 and $0.30 \mathrm{~h}^{-1}$. The fluxes through reactions located around important branch points of the metabolism were compared, i.e. the split between the pentose phosphate and the Embden-Meyerhoff-Parnas pathways. Also the model was used to show the probable existence of a redox shunt across the inner mitochondrial membrane consisting of the reactions catalysed by the mitochondrial and the cytosolic alcohol dehydrogenase. Finally it was concluded that cytosolic isocitrate dehydrogenase is probably not present during growth on glucose. The importance of basing the flux analysis on accurate measurements was demonstrated through a sensitivity analysis. It was found that the accuracy of the measurements of $\mathrm{CO}_{2}$, ethanol, glucose, glycerol and protein was critical for the correct calculation of the flux distribution.
\end{abstract}

Keywords: anaerobic growth, Saccharomyces cerevisiae, stoichiometric model, continuous culture, flux distribution

\section{INTRODUCTION}

Quantification of metabolic fluxes is one of the most important aspects of physiological studies, especially in connection with studies of metabolite production where the aim is to direct as much carbon as possible from the substrate into the metabolic product. A powerful technique for determination of the fluxes through various pathways is Metabolic Flux Analysis (MFA), where the intracellular fluxes are calculated using a stoichiometric model for all the major intracellular reactions. As input to the calculations a set of measured fluxes, typically the uptake rates of substrates and secretion rates of metabolites, is used (Vallino \& Stephanopoulus, 1993; Jørgensen et al., 1995). Apart from flux calculations leading to determination of the carbon flows inside the cell, MFA is useful for:

(1) Calculation of non-measured extracellular fluxes. Normally the number of fluxes that can be measured is larger than what is needed for the calculation of the 
intracellular fluxes. In this case it is possible to calculate some of the extracellular fluxes, e.g. the production of various by-products, by use of the stoichiometric model and the measured rates.

(2) Calculation of maximum theoretical yields. Based on a stoichiometric model it is possible to calculate the maximum theoretical yield of a given metabolite if a set of constraints is specified. This has been illustrated by Stephanopoulos \& Vallino (1991) who calculated the maximum theoretical yield of lysine on glucose in Corynebacterium glutamicum and by Jørgensen et al. (1995) who calculated the maximum theoretical yield of penicillin on glucose in Penicillium chrysogenum under the assumption of no growth.

(3) Identification of the existence of different pathways. Formulation of the stoichiometric matrix, which is the basis for MFA, requires detailed information on the biochemistry. However, for many micro-organisms certain details about the pathway stoichiometries are not known, and it may not be known whether a given pathway is active. Furthermore, there may be several isoenzymes with functions which are not known in detail. By calculating the metabolic fluxes with different sets of cellular pathways it may be possible to identify the set of pathways which is most likely to be active, or get indications of the function of different isoenzymes and/or pathways. This approach is illustrated in one of the first applications of MFA, where Aiba \& Matsuoka (1979) examined various anaplerotic pathways in citrate-producing Candida lipolytica.

(4) Examination of the influence of alternative pathways on the distribution of fluxes. In connection with optimization of metabolite production it may be possible to identify one or several constraints for increasing the yield of a particular metabolite on the substrate or for increasing the flux leading to the desired metabolite. Here various scenarios can be compared to examine whether insertion of a new pathway or an isoenzyme (or perhaps deletion of an isoenzyme) can help to remove the constraint, and thereby lead to an increased flux towards the desired metabolite. This approach is especially of value in connection with metabolic engineering of microorganisms, where rational changes in the gene base are introduced with the aim of improving the performance of the micro-organism (Bailey, 1991).

(5) Identification of possible rigid branch points (or nodes) in the cellular pathways. Through comparison of the distribution of fluxes at different operating conditions it is possible to identify whether a pathway node is rigid or flexible (Stephanopoulos \& Vallino, 1991). Thus in lysine-producing corynebacterium it is found that the nodes at glucose-6-phosphate, pyruvate and oxaloacetate are flexible, whereas the phosphoenolpyruvate node is rigid (Stephanopoulos \& Sinskey, 1993; Vallino \& Stephanopoulos, 1993).

In this paper we will use MFA for several of the abovementioned purposes. The metabolic fluxes in Saccharomyces cerevisiae will be calculated at different dilution rates in an anaerobic, glucose-limited continuous cultures providing a basis for the analysis of differences in the metabolism between the wild-type strain and genetically modified strains derived from the wild-type strain. Furthermore, the MFA is used in the study of various isoenzymes, which are active during anaerobic growth of $S$. cerevisiae, e.g. alcohol dehydrogenase $(\mathrm{ADH})$ and isocitrate dehydrogenase, providing new information about the distribution and role of these enzymes during anaerobiosis.

\section{Theory of MFA}

The basis of MFA is a stoichiometric model describing the biochemistry of the micro-organism (Papoutsakis, 1984; Vallino \& Stephanopoulos, 1990, 1993; Jørgensen et al., 1995). The stoichiometry of the considered intracellular reactions is specified in a stoichiometric matrix. From mass balancing around the intracellular metabolites, the reaction rates (or metabolic fluxes) are calculated based on an assumption of pseudosteady state in the intracellular concentrations of the metabolites and measurement of a few reaction rates, e.g. glucose uptake rate (Vallino \& Stephanopoulos, 1993). Furthermore, to quantify the drain of metabolites for biomass synthesis it is nessesary to know the macromolecular composition of the biomass (Jørgensen et al., 1995).

If the stoichiometric matrix is singular, two or more reactions are linearly dependent and a unique solution of the set of mass balances cannot be determined. A typical singularity appears when the three reactions of ammonia assimilation catalysed by glutamate dehydrogenase II, glutamine synthase (GOGAT) and glutamine synthetase (GS) all are included in the stoichiometric matrix. Singularities can only be eliminated by changing the metabolic network, e.g. by adding or removing reactions. However, this must be done with due respect to the underlying biochemistry. In vitro enzyme assays can be used as a tool to determine the presence or absence of reactions and may also add a constraint to the model, e.g. an estimate of the ratio between two fluxes can be obtained.

Any stoichiometric model should be subjected to a sensitivity analysis to detect if the calculated rates are sensitive to errors in the measurements. For this purpose the sensitivity analysis described by Vallino \& Stephanopoulos (1990) is useful.

Finally, it should be mentioned that compartmentation of the cell can be achieved simply by treating a given compound found in more than one compartment as different compounds in the model.

\section{A stoichiometric model for S. cerevisiae}

The general biochemistry of the primary and secondary metabolism in $S$. cerevisiae is well known. Detailed information concerning the reactions in the stoichio- 
Table 1. References used in the formulation of the stoichiometric model

\begin{tabular}{|c|c|}
\hline Reaction & Reference \\
\hline \multicolumn{2}{|l|}{ Uptake } \\
\hline Glucose & Bisson \& Fraenkel (1983); McClellan \& Bisson (1988) \\
\hline Ammonia & $\begin{array}{l}\text { Roon et al. (1975); Cooper (1982); Cartwright et al. } \\
\text { (1989) }\end{array}$ \\
\hline Sulphate & Breton \& Surdin-Kerjan (1977); Roomans et al. (1979) \\
\hline Phosphate & Cockburn et al. (1975) \\
\hline \multicolumn{2}{|l|}{ Catabolism } \\
\hline EMP pathway, PP pathway & Sols et al. (1971); Gancedo \& Serrano (1989) \\
\hline \multicolumn{2}{|l|}{ Anabolism } \\
\hline TCA cycle & $\begin{array}{l}\text { Schatzmann (1975); Wales et al. (1980); Gancedo \& } \\
\text { Serrano (1989); Visser et al. (1994) }\end{array}$ \\
\hline Anaplerotic reaction & Haarasilta \& Taskinen (1977) \\
\hline Amino acid synthesis & Jones \& Fink (1982) \\
\hline Polymerization of amino acids & Tuite (1989) \\
\hline Nucleotide synthesis & Jones \& Fink (1982) \\
\hline Lipid synthesis & Stryer $(1988)$ \\
\hline Carbohydrate synthesis & Farkas (1989) \\
\hline \multicolumn{2}{|l|}{ Product formation } \\
\hline Ethanol & $\begin{array}{l}\text { Lutsdorf \& Megnet (1968); von Jagow \& Klingenberg } \\
\text { (1970); Ciriacy (1979); Danielsson \& Moseley (1986) }\end{array}$ \\
\hline Glycerol & Gancedo et al. (1968); Oura (1977) \\
\hline Acetate & Seegmiller (1955); Tamaki \& Hama (1982) \\
\hline Product secretion & $\begin{array}{l}\text { Gancedo et al. (1968); Jones \& Greenfield (1982); } \\
\text { Cartwright et al. (1989); Jones (1989); Stanley \& } \\
\text { Pamment (1993) }\end{array}$ \\
\hline
\end{tabular}

metric model can be obtained in the references listed in Table 1.

The composition of protein, DNA, RNA and lipids is assumed to be constant under all growth conditions. This assumption is supported by measurements of the amino acid composition of the protein under various growth conditions. Whereas the amino acid composition of the protein was measured (data not shown), we use the composition of nucleotides in RNA and DNA obtained by de Robichon-Szulmajster \& Surdin-Kerjan (1971) and the lipid composition described by Rattray (1988). The unsaturated fatty acids and the sterols are assumed to be supplied by respectively the Tween 80 and the ergosterol content of the medium. Specific properties of the stoichiometric model are described in the following.

Isoenzymes. Three isoenzymes of ADH (ADH I, ADH II and ADH III) have been identified in S. cerevisiae (Lutstorf \& Megnet, 1968; Danielsson \& Moseley, 1986). The cytosolic ADH I is constitutively expressed during anaerobic growth on glucose and is responsible for the formation of ethanol. ADH II is mainly associated with growth on ethanol (Ciriacy, 1979), and is therefore not active under the conditions applied in this work. The function of the mitochondrial ADH III is not known but it has been postulated to function as a shuttle of redox equivalents between mitochondria and the cytosol (von Jagow \& Klingenberg, 1970). Measure- ments carried out in this work have shown that ADH III is active during anaerobic growth on glucose (see Results). Hence, the model includes two reactions where acetaldehyde is reduced to ethanol but localized in different compartments (reactions 9 and 37).

Two isoenzymes of aldehyde dehydrogenase exist (Seegmiller, 1955; Tamaki \& Hama, 1982). The mitochondrial enzyme is repressed by glucose and can use both $\mathrm{NAD}^{+}$and $\mathrm{NADP}^{+}$as cofactors whereas the other is localized in the cytosol and is specific for $\mathrm{NADP}^{+}$. The formation of acetate by these two enzymes has been pooled into one reaction (reaction 10) in which the stoichiometric values for NADH and NADPH has been determined from measured in vitro activities of the enzymes (see Results). If both enzymic reactions are included a singularity in the stoichiometric matrix arises. This singularity is avoided by the chosen procedure.

Three isoenzymes of isocitrate dehydrogenase have been isolated (IDH, IDP1 and IDP2) (Keys \& McAlisterHenn, 1990; Cupp \& McAlister-Henn, 1991, 1992; Haselbeck \& McAlister-Henn, 1991; Loftus et al., 1994). The $\mathrm{NAD}^{+}$-dependent IDH is localized in the mitochondria and is important for the function of the TCA cycle whereas the function of the two $\mathrm{NADP}^{+}$-dependent isoenzymes IDP1 and IDP2 localized in the mitochondria and cytosol, respectively, have not yet been clearly established. The role of IDP1 may be in the formation of 
$\mathrm{NADPH}$ in the mitochondria for the synthesis of amino acids in this compartment. Furthermore, speculations have been made whether the two enzymes may play a role in the transfer of redox equivalents between cytosol and mitochondria (Lupiañez et al., 1974; Machado et al., 1975). Recent studies have suggested that IDP2 is not active during growth on glucose. Consequently only IDH and IDP1 are included in the model (reactions 17 and 22) although the consequences of including IDP2 in the model will be analysed (see Results).

Synthesis of cytosolic acetyl-CoA. Synthesis of cytosolic acetyl-CoA can occur in three ways in yeasts: (1) from acetate in a reaction catalysed by acetyl-CoA synthetase (Frenkel \& Kitchens, 1977; Klein \& Jahnkle, 1979; van der Berg \& Steensma, 1995), (2) by hydrolysis of citrate to oxaloacetate and acetyl-CoA in a reaction catalysed by ATP: citrate lyase (Boulton \& Ratledge, 1981), and (3) by transport of mitochondrial acetyl-CoA to the cytosol in the form of acetylcarnitine in a reaction catalysed by carnitine acetyltransferase (Kohlhaw \& Tan-Wilson, 1977). Since a thorough study of the activity of ATP : citrate lyase in a large number of yeasts failed to find any activity of the enzyme in $S$. cerevisiae (Boulton \& Ratledge, 1981), and since measurements of the activity of carnitine acetyltransferase carried out in this study showed no activity under the present growth conditions (see Results) only the reaction catalysed by acetyl-CoA synthetase has been included in the model (reaction 21).

Ammonia assimilation. Glutamate can be synthesized by two systems in S. cerevisiae: (1) glutamate dehydrogenase; (2) a two-step pathway catalysed by GS and GOGAT (Roon et al., 1974; Mitchell \& Magasanik, 1983; Holmes et al., 1991). Measurements of the specific activities of both the NADPH-dependent and the NADH-dependent glutamate dehydrogenase and GOGAT carried out in this work (see Results) showed that the activity of the former enzyme exceeds the activities of the two other enzymes by a factor of 40 while no activity of GS could be detected. Hence, only the reaction catalysed by the NADPH-dependent glutamate dehydrogenase is included in the model.

ATP consumption. ATP is included as a metabolite in the stoichiometric matrix. To account for maintenance and futile cycles, a reaction is included to dissipate excess ATP (reaction 35). Furthermore, it is assumed that ATP and GTP can be interconverted by means of nucleoside diphosphokinases (Stryer, 1988).

Compartmentation. To obtain a realistic description of the redox levels in both the mitochondria and the cytosol, compartmentation is considered in the model. This compartmentation is achieved by treating compounds unable to cross the inner mitochondrial membrane as two different compounds, one present in the cytosol and the other in the mitochondria. This has been done for NADH, NADPH and fumarate since no transport systems for these compounds exist (LaNoue \& Schoolwerth, 1979; Krämer \& Palmieri, 1992). A compartmentation is also made for acetyl-CoA since no activity could be determined for carnitine acetyltransferase (see Results). This compartmentation implies that reactions consuming and producing the four compounds must balance in each compartment. S. cerevisiae has a number of carriers for di- and tricarboxylic acids that allows exchange of the TCA-cycle intermediates between the two compartments. The function of these carriers has been established in anaerobically grown cells (Perkins et al., 1973). Carriers for all intermediates of the TCA cycle, except for succinyl-CoA, have been reported, which implies that no compartmentation of these compounds is included in the model. Furthermore, a number of amino acids are partly synthesized in the mitochondria (Jones \& Fink, 1981), and it is assumed that the intermediates of these reactions can be transported across the inner mitochondrial membrane.

\section{Summary of the model description}

The model contains 43 compounds and 37 pathway reactions. A zero volumetric production rate (pseudosteady state) is assumed for 27 compounds resulting in a model with 10 degrees of freedom. Thirteen compounds are measured: acetate, $\mathrm{CO}_{2}$, ethanol, glucose, glycerol, $\mathrm{NH}_{4}^{+}$, pyruvate, succinate, carbohydrates, DNA, lipids, proteins and RNA. The remaining three compounds are not measured: cytosolic fumarate, malate and $\mathrm{SO}_{4}^{2-}$. We have chosen to exclude ethanol and $\mathrm{NH}_{4}^{+}$from the list of measured compounds which are used to calculate the metabolic fluxes. Thus, the calculated fluxes of ethanol and $\mathrm{NH}_{4}^{+}$can be used to validate the flux model. The condition number of the stoichiometric matrix (Vallino \& Stephanopoulos, 1990) is 22, implying that the model is numerically robust. All reactions and compounds of the stoichiometric matrix are listed in Appendix A.

\section{METHODS}

Micro-organism and its maintenance. S. cerevisiae CBS 8066 was obtained from the Centraal Bureau voor Schimmelcultures (Delft, The Netherlands). The strain was maintained at $4{ }^{\circ} \mathrm{C}$ on YPG agar plates, monthly prepared from a lyophilized stock kept at $-80^{\circ} \mathrm{C}$. The bioreactor was inoculated to an initial biomass concentration of $1 \mathrm{mg} \mathrm{l}^{-1}$ with a pre-culture grown in unbaffled shake flasks at $30^{\circ} \mathrm{C}$ and 100 r.p.m. for 24 h.

Media. The yeast was cultivated in a mineral medium prepared according to the method of Verduyn et al. (1990). Vitamins were added by sterile filtration following heat-sterilization of the medium. The feed concentration of glucose and $\left(\mathrm{NH}_{4}\right)_{2} \mathrm{SO}_{4}$ was $25 \mathrm{~g} \mathrm{l}^{-1}$ and $7.5 \mathrm{~g} \mathrm{l}^{-1}$, respectively. Growth of $S$. cerevisiae under anaerobic conditions requires the supplementary addition to the medium of ergosterol and unsaturated fatty acids, typically in the form of Tween 80 (Andreasen \& Stier, 1953; Libudzisz et al., 1986). Ergosterol and Tween 80 were dissolved in $96 \%(\mathrm{v} / \mathrm{v})$ ethanol and the solution was autoclaved at $121{ }^{\circ} \mathrm{C}$ for $5 \mathrm{~min}$. The final concentrations of ergosterol and Tween 80 in the medium were $4.2 \mathrm{mg}$ (g dry weight $^{-1}$ and $175 \mathrm{mg}$ (g dry weight) ${ }^{-1}$, respectively. To prevent foaming, $75 \mu \mathrm{l}$ antifoam $\mathrm{l}^{-1}$ (Sigma) was added to the medium. 
Cultivation conditions. Anaerobic continuous cultivations were performed at $30^{\circ} \mathrm{C}$ and at a stirring speed of 1000 r.p.m. in an in-house-manufactured bioreactor with a working volume of $11 \mathrm{pH}$ was kept constant at 5.00 by addition of $2 \mathrm{M}$ $\mathrm{KOH}$. The bioreactor was equipped with an off-gas condenser cooled to $2^{\circ} \mathrm{C}$. The bioreactor was continuously sparged with $\mathrm{N}_{2}$ containing less than 5 p.p.m. $\mathrm{O}_{2}$, obtained by passing $\mathrm{N}_{2}$ of a technical quality (AGA 3.8), containing less than 100 p.p.m. $\mathrm{O}_{2}$, through a column $(250 \times 30 \mathrm{~mm})$ filled with copper flakes and heated to $400^{\circ} \mathrm{C}$. The column was regenerated daily by sparging it with $\mathrm{H}_{2}$ (AGA 3.6). A mass-flow controller (Bronkhorst HiTec F201C) was used to keep the gas flow into the bioreactor constant at $0.501 \mathrm{~min}^{-1}$. The medium reservoir was extensively sparged with $\mathrm{N}_{2}$ containing less than 5 p.p.m. $\mathrm{O}_{2}$ and was then sealed. To avoid formation of a vacuum when withdrawing medium from the reservoir, it was connected to a gas-impermeable bag filled with $\mathrm{N}_{2}$ containing less than 5 p.p.m. $\mathrm{O}_{2}$. Norprene tubing (Cole-Parmer Instruments) was used throughout to minimize diffusion of oxygen into the bioreactor.

Determination of dry weight. Dry weight was determined gravimetrically using nitrocellulose filters (pore size $0.45 \mu \mathrm{m}$; Gelman Sciences). The filters were pre-dried in a microwave oven (Moulinex FM B 935Q) for $10 \mathrm{~min}$. A known volume of culture liquid was filtered and the filter was washed with an equal volume of demineralized water followed by drying in a microwave oven for $15 \mathrm{~min}$. The relative standard deviation (RSD) of the determinations was less than $1.5 \%$ based on triplicate determinations $(n=3)$.

Analysis of medium compounds. Cell-free samples were withdrawn directly from the bioreactor through a capillary connected to a $0.45 \mu \mathrm{m}$ filter. Samples were subsequently stored at $-40^{\circ} \mathrm{C}$. Glucose, ethanol, glycerol, acetic acid, pyruvic acid and succinic acid were determined by HPLC using an HPX-87H Aminex ion-exclusion column (RSD $<$ $0.6 \%, n=3)$. The column was eluted at $60^{\circ} \mathrm{C}$ with $5 \mathrm{mM}$ $\mathrm{H}_{2} \mathrm{SO}_{4}$ at a flow rate of $0.6 \mathrm{ml} \mathrm{min}{ }^{-1}$. Pyruvic acid and acetic acid were determined with a Waters 486 UV meter at $210 \mathrm{~nm}$, whereas the other compounds were determined with a Waters 410 refractive index detector. The two detectors were connected in series with the UV detector first. The glycerol measurement was verified by measuring the concentration of the compound with a kit purchased from Boehringer Mannheim, while the glucose measurement was verified using a flow-injection analyser (Benthin et al., 1994). Ammonium was determined using a flow-injection analyser as described by Christensen et al. (1991) ( $\mathrm{RSD}=1.0 \%, n=3)$. The $\mathrm{CO}_{2}$ concentration in the off-gas was determined using a Brüel $\&$ Kjær 1308 acoustic gas analyser ( $R$ SD $=0.02 \%$ ) (Christensen et al., 1995). In a separate experiment, the off-gas from the bioreactor was bubbled through liquid nitrogen and the ethanol concentration in the frozen mixture of water, ethanol and acetaldehyde was determined by HPLC after evaporation of the $\mathrm{N}_{2}$. Hereby the loss of ethanol through the reflux condenser of the bioreactor was determined to be between 4 and $9 \%$ of the ethanol formed by the bioreaction depending on the dilution rate (Schulze, 1995). In the carbon balances (Table 2), the measured ethanol fluxes were corrected for this loss through evaporation.

Analysis of intracellular compounds. Culture liquid was withdrawn from the bioreactor into an ice-cooled beaker. For each analysis, an adequate amount of sample was centrifuged, washed twice with $0.9 \%(\mathrm{w} / \mathrm{w}) \mathrm{NaCl}$ and resuspended in buffer. Samples were immediately frozen in liquid nitrogen and subsequently stored at $-40^{\circ} \mathrm{C}$. The protein content of whole cells was determined by a modified Biuret method according to Verduyn et al. (1990) ( $\mathrm{RSD}=2 \cdot 5 \%, n=3)$. RNA measurements were determined as described by Benthin $e t$ al. (1991) $(\mathrm{RSD}=2.0 \%, n=3)$. Trehalose and glycogen were determined enzymically as described by Schulze et al. (1995) (RSD $=2.5 \%, n=3$ ). The total carbohydrate content was determined using the phenol method as described by Herbert et al. (1971). DNA measurement was by Burton's method as described by Herbert et al. (1971). Mannan and glucan were extracted by treating cells with hot acid $\left(75^{\circ} \mathrm{C}, 1 \mathrm{M} \mathrm{HCl}\right)$ for $6 \mathrm{~h}$, whereafter mannan was precipitated with Fehling's reagent. After washing the precipitate with ethanol containing $\mathrm{HCl}$, the content of mannan was quantified by the phenol method. Lipid was extracted from the cells using a mixture of chloroform and methanol $(2: 1 \mathrm{w} / \mathrm{w})$ followed by washing with $0.9 \% \mathrm{NaCl}$. Subsequently, the solvents were removed by sparging the samples with $\mathrm{N}_{2}$ whereafter the amount of lipid was quantified gravimetrically. The amino acid composition of the protein was determined as described by Barkholt $\&$ Jensen (1989) (RSD $=1.8 \%, n=3$ ). The intracellular pool of free amino acids was extracted by boiling cells in $\mathrm{H}_{2} \mathrm{O}$ for $15 \mathrm{~min}$ (Malaney et al., 1989). The amino acid content of the extract was determined as described for the protein composition.

Preparation of cell-free extracts. Culture liquid was withdrawn from the bioreactor into an ice-cooled beaker, centrifuged and washed twice with $10 \mathrm{mM}$ potassium phosphate buffer ( $\mathrm{pH} 7 \cdot 5,2^{\circ} \mathrm{C}$ ) containing $2 \mathrm{mM}$ EDTA. Subsequently the cells were resuspended in $4.2 \mathrm{ml} 100 \mathrm{mM}$ potassium phosphate buffer $\left(\mathrm{pH} 7 \cdot 5,2^{\circ} \mathrm{C}\right.$ ) containing $2 \mathrm{mM} \mathrm{MgCl}_{2}$, followed by immediate freezing in liquid nitrogen and storage at $-40^{\circ} \mathrm{C}$. Prior to analysis, $0 \cdot 22 \mathrm{ml} 20 \mathrm{mM}$ DTT was added to the samples, whereafter they were distributed into precooled $2 \mathrm{ml}$ Eppendorf tubes containing $0.75 \mathrm{ml}$ glass beads (size $0.25-0.50 \mathrm{~mm}$ ). The cells were disrupted in a bead mill for $12.5 \mathrm{~min}\left(0^{\circ} \mathrm{C}\right)$. The test tubes were centrifuged (20000 r.p.m., $20 \mathrm{~min}, 0^{\circ} \mathrm{C}$ ), whereafter the supernatants were pooled in one test tube. During the following analyses the extract was kept on ice.

Analysis of in vitro enzyme activities. Enzyme assays were performed at $30^{\circ} \mathrm{C}$ using a Shimadzu UV-260 spectrophotometer at $30^{\circ} \mathrm{C}$. Reaction rates, corrected for endogenous rates, were proportional to the amount of extract added. All enzyme activities are expressed as $\mu \mathrm{mol}$ substrate converted $\min ^{-1}$ (mg protein) $)^{-1}$ as determined by the Lowry method. Alcohol dehydrogenases I and III (EC 1.1.1.1) were assayed as described by Verduyn et al. (1992). Acetyl-CoA synthetase (EC 6.2.1.1), hexokinase (EC 2.7.1.1), glucose-6-phosphate 1-dehydrogenase (EC 1.1.1.49) and aldehyde dehydrogenase $\left[\mathrm{NAD}(\mathrm{P})^{+}\right.$and $\left.\mathrm{NADP}^{+}\right]$(EC 1.2.1.5 and $\mathrm{EC}$ 1.2.1.4, respectively) were assayed as described by Postma et al. (1989). Glutamate dehydrogenase $\left(\mathrm{NAD}^{+}\right.$and $\left.\mathrm{NADP}^{+}\right)(\mathrm{EC}$ 1.4.1.5 and EC 1.4.1.4, respectively) were assayed as described by Bruinenberg et al. (1983). Glutamine synthetase (EC 6.3.1.2) and glutamate synthase (GOGAT) (EC 1.4.1.14) were assayed as described by Holmes et al. (1989). The functionality of the GS assay was verified with GS purchased from Sigma. The assay of carnitine acetyltransferase (EC 2.3.1.7) was performed essentially as the acetyl-CoA synthetase assay except that acetyl carnitine was used instead of acetate as substrate. $\mathrm{MgSO}_{4}$ was not added to the assay due to the inhibitory effect of magnesium ions on the enzyme. The functionality of the assay was verified with a carnitine acetyltransferase purchased from Sigma. For one dilution rate $\left(D=0.1 \mathrm{~h}^{-1}\right)$, the assay for carnitine acetyltransferase was compared with the assay described by Fritz $\&$ Schulz (1965). 


\section{RESULTS AND DISCUSSION}

\section{Formation of biomass and products}

Table 2 summarizes the yields on glucose of the most important products in the anaerobic, glucose-limited continuous cultures. It is seen that about $80 \%(\mathrm{w} / \mathrm{w})$ of the consumed glucose is converted into ethanol and carbon dioxide and that these yields are virtually independent of the specific growth rate. On a molar basis $Y_{\mathrm{sc}}\left(1.63 \mathrm{~mol} \mathrm{~mol}^{-1}\right)$ is slightly higher than $Y_{\text {seton }}$ $\left(1.49 \mathrm{~mol} \mathrm{~mol}^{-1}\right)$ since $\mathrm{CO}_{2}$ is formed not only in the synthesis of ethanol but also in a number of anabolic reactions. A little less than $10 \%(\mathrm{w} / \mathrm{w})$ of the glucose is converted into biomass and another $10 \%(\mathrm{w} / \mathrm{w})$ ends up as glycerol whereas approximately $1 \%(\mathrm{w} / \mathrm{w})$ is converted into various organic acids. $Y_{\text {sx }}$ decreases slighty with increasing dilution rate whereas $Y_{\text {sgly }}$ increases. $Y_{\text {ssue }}$ is practically unaffected by the dilution rate whereas $Y_{\text {spyr }}$ and especially $Y_{\text {sace }}$ increase when the dilution rate is increased from 0.1 to $0.4 \mathrm{~h}^{-1}$. It is seen that the measured compounds can account for about $98 \%(\mathrm{w} / \mathrm{w})$ of the consumed glucose (c.f. Table 2$)$. The specific rates of glucose uptake and ethanol formation (Fig. 1) were found to be linear functions of the specific growth rate in analogy with the maintenance model of Pirt (1965):

$r_{\mathrm{i}}=\gamma_{\mathrm{xi}} \cdot \mu+m_{\mathrm{i}}$

The equation ascribes the consumption of a given substrate (or the formation of a product) to two processes, a growth associated and a non-growth associated. For $D<0 \cdot 2 \mathrm{~h}^{-1}$ the specific rate of glycerol formation also follows the linear relation in equation (1) but for $D>0 \cdot 2 \mathrm{~h}^{-1}$ the glycerol production increases more than linearly with $\mu$ (Fig. 1). Table 3 lists the stoichiometric and the maintenance coefficients for ethanol, glucose and glycerol. It is observed that all the maintenance coefficients are very close to zero.

The data obtained in this study are qualitatively in accordance with previously reported results for $S$.

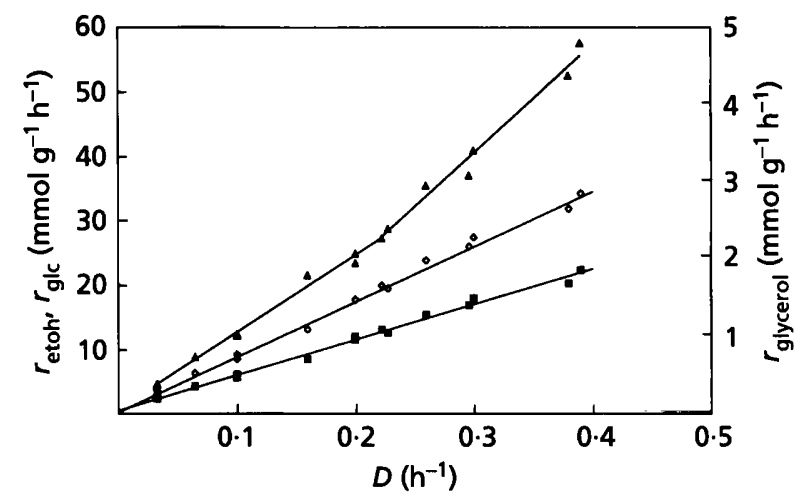

Fig. 1. The specific uptake rate of glucose $(\square)$ and the specific production rates of ethanol $(\bullet)$ and glycerol $(\boldsymbol{\Delta})$ as functions of the dilution rate.

Table 3. Stoichiometric $(\gamma)$ and maintenance $(m)$ coefficients for the glucose-limited continuous culture

\begin{tabular}{|lccc|}
\hline Coefficient & $\begin{array}{c}\text { mmol (g dry } \\
\text { weight) }\end{array}$ & Coefficient & $\begin{array}{c}\text { mmol (g dry } \\
\text { weight) }{ }^{-1} \mathbf{h}^{-1}\end{array}$ \\
\hline$\gamma_{\text {xetoh }}$ & 85.05 & $m_{\text {etoh }}$ & $0.15 \pm 0.27$ \\
$\gamma_{\text {xgle }}{ }^{*}$ & 54.32 & $m_{\text {glc }}$ & $0.45 \pm 0.52$ \\
$\gamma_{\text {xgly }}$ & 10.01 & $m_{\text {gly }}$ & $0.02 \pm 0.07$ \\
\hline
\end{tabular}

*Only valid for $D<0.2 \mathrm{~h}^{-1}$.

cerevisiae CBS 8066 (Verduyn et al., 1990; Lidén et al., 1995). All the reported results indicate that $Y_{\text {seton }}$ is independent of $D$ and that $Y_{\text {sgly }}$ and $Y_{\text {sace }}$ increase with increasing $D$. However, Verduyn et al. (1990) do not find the linear relationships between $r_{\text {etoh }}, r_{\text {gle }}$ and $\mu$ that are shown in Fig. 1 - the reason being that they measure a decreasing biomass concentration and hence a decreasing $Y_{\mathbf{s x}}$ (from 0.103 to $0.086 \mathrm{~g} \mathrm{~g}^{-1}$ ) when $D$

Table 2. Yields on glucose for an anaerobic, glucose-limited continuous culture at various dilution rates

$Y_{\mathrm{sx}}$ was calculated using molecular masses calculated from the measured biomass compositions. These values varied between $28 \cdot 0 \mathrm{~g} \mathrm{C}^{\mathrm{sxol}} \mathrm{m}^{-1}$ at $D=0 \cdot 1 \mathrm{~h}^{-1}$ and $27 \cdot 1 \mathrm{~g} \mathrm{C}^{-\mathrm{mol}^{-1}}$ at $D=0.4 \mathrm{~h}^{-1}$.

\begin{tabular}{|c|c|c|c|c|}
\hline \multirow[t]{2}{*}{ Compound } & \multicolumn{4}{|c|}{ Yield on glucose $\left[\mathrm{C}-\mathrm{mol}(\mathrm{C}-\mathrm{mol} \text { glucose })^{-1}\right]$} \\
\hline & $D=0 \cdot 10 h^{-1}$ & $D=0.20 \mathrm{~h}^{-1}$ & $D=0.30 \mathrm{~h}^{-1}$ & $D=0.40 \mathrm{~h}^{-1}$ \\
\hline Carbon dioxide $\left(Y_{\mathrm{sc}}\right)$ & $0 \cdot 272$ & 0.273 & $0 \cdot 267$ & $0 \cdot 261$ \\
\hline Ethanol $\left(Y_{\text {seton }}\right)$ & 0.497 & 0.496 & 0.494 & 0.497 \\
\hline Biomass $\left(Y_{\mathrm{sx}}\right)$ & $0 \cdot 107$ & 0.105 & $0 \cdot 105$ & $0 \cdot 104$ \\
\hline Glycerol $\left(Y_{\mathrm{sgly}}\right)$ & 0.086 & 0.091 & 0.095 & $0 \cdot 109$ \\
\hline Succinic acid $\left(Y_{\text {ssuc }}\right)$ & 0.003 & 0.003 & 0.002 & 0.002 \\
\hline Acetic acid $\left(Y_{\text {sace }}\right)$ & 0.002 & 0.003 & 0.006 & $0 \cdot 010$ \\
\hline Pyruvic acid $\left(Y_{\text {spyr }}\right)$ & 0.001 & 0.002 & 0.003 & 0.004 \\
\hline Total & 0.968 & 0.973 & 0.972 & 0.987 \\
\hline
\end{tabular}


increases from $0 \cdot 10$ to $0 \cdot 27 \mathrm{~h}^{-1}$. Since the value of $Y_{\mathrm{sx}}$ at $D=0 \cdot 10 \mathrm{~h}^{-1}$ obtained in this study is virtually identical to the value observed by Verduyn et al. (1990), it is unlikely that the present culture has been limited by unsaturated fatty acids. The decrease in $Y_{\mathrm{sx}}$ observed by Verduyn et al. (1990) may be due to excess residual medium concentration of unsaturated fatty acids at high dilution rates which could lead to uncoupling of anabolic and catabolic processes (Viegas et al., 1989) and thus, a decrease in $Y_{\mathrm{sx}}$. However, the $\gamma$ values listed in Table 3 are in good accordance with the values observed by Verduyn et al. (1990) at dilution rates lower than $0.20 \mathrm{~h}^{-1}$. Lidén et al. (1995) reports similar values although the maximum value of $Y_{\mathrm{sx}}$ is found to be $0.09 \mathrm{~g}$ $\mathrm{g}^{-1}$ indicating that the culture may have been fed with a suboptimal concentration of unsaturated fatty acids

\section{Cellular composition}

Measurements of the cellular composition are necessary to structure the flux of carbon to biomass, and especially if the cellular composition changes with the operating conditions it is important to consider the differences in fluxes to the different macromolecular pools. In this study, the cellular composition was therefore determined at four different dilution rates (see Table 4). The most important variation in the cellular composition is that the amount of active machinery, i.e. protein and RNA, increases linearly with increasing dilution rate at the expense of carbohydrates. The cellular content of other components is virtually independent of the dilution rate. From Table 4 it is seen that the measurements can account for approximately $100 \%$ of the cell mass, but since the pool of e.g. glycolytic intermediates has not been measured, some of the analyses have a small overlap. However, the results indicate that no major cellular component has been left out. The values listed in Table 4 are in good accordance with previously reported values for the cellular composition of $S$. cerevisiae (Küenzi \& Fiechter, 1972; Oura, 1972; Watson, 1976; Waldron, 1977; Furukawa et al., 1983; Verduyn et al., 1990).

\section{Enzyme activities}

In vitro activities of 12 enzymes were measured to clarify ambiguities with respect to the presence or absence of an enzyme and the cofactor-specificity of certain enzymes at various growth conditions.

Fig. 2(a) illustrates the in vitro enzyme activities of key enzymes involved in formation and consumption of acetate. The activities of the two isoenzymes of aldehyde dehydrogenase were assayed to determine in which conditions the enzymes were active. From Fig. 2(a) it is apparent that the $\mathrm{NAD}(\mathrm{P})^{+}$-dependent enzyme is not active at $D>0.3 \mathrm{~h}^{-1}$. Thus, the model includes both enzymes in the ratio determined by the enzyme assay except at $D>0.3 \mathrm{~h}^{-1}$ where only the $\mathrm{NADP}^{+}$-dependent enzyme is included. No activity of carnitine acetyltransferase could be detected in the applied growth conditions indicating that cytosolic acetyl-CoA does not originate from the mitochondria. The activity of acetylCoA synthetase increased with the dilution rate, indicating that this enzyme is involved in synthesis of cytosolic acetyl-CoA.

Fig. 2(b) shows the in vitro activities of the enzymes involved in the assimilation of ammonia. It is apparent that at all tested dilution rates the activity of the NADPH-dependent glutamate dehydrogenase is more than 30-fold higher than the activity of GOGAT and the NADH-dependent glutamate dehydrogenase. Thus, it seems reasonable to include only the NADPH-dependent enzyme in the model. No activity of GS could be detected, indicating that the enzyme is labile and therefore lost in the preparation of the cell-free extract.

The specific enzyme activities of the two isoenzymes of alcohol dehydrogenase, ADH I and ADH III, are shown in Fig. 2(c). It is seen that both isoenzymes exhibit activity although the activity of ADH III is very low. The activity of this enzyme is nevertheless important since $\mathrm{ADH}$ III is localized in the mitochondria and may function as a shuttle of redox equivalents between the cytosol and the mitochondria (von Jagow \& Klingenberg, 1970).

Finally, the activities of hexokinase and glucose-6phosphate dehydrogenase were determined in an attempt to verify the split between the PP and the EMP pathway predicted by the model. Fig. 2(d) shows the ratio between the activities of the two enzymes as a function of the dilution rate.

\section{Flux distributions}

Figs 3 and 4 show the flux distributions at $D=0 \cdot 1$ and $0 \cdot 3 \mathrm{~h}^{-1}$, respectively. The fluxes are expressed in C-mol $(\mathrm{g} \text { dry } w t)^{-1} h^{-1}$ and have been normalized with respect to the glucose uptake. It is seen that the split between the $\mathrm{PP}$ and the EMP pathways increases with increasing specific growth rate. This can be explained by an increased demand for NADPH which is the result of an increase in the cellular content of especially protein but also of RNA. Also the flux from acetaldehyde to acetate, which is the second source of NADPH production in the cytosol, increases with increasing dilution rate.

Based on the measured enzyme activities, the split between the PP and the EMP pathways is $1: 10$ independent of dilution rate (Fig. $2 \mathrm{~d}$ ). The calculated split between the two pathways vary between $1: 16$ at a low dilution rate and $1: 13$ at a high dilution rate. The difference between the measured and the calculated split is likely to be caused by the differences between in vitro and in vivo conditions.

The flux to glycerol is observed to increase with $\mu$ as a result of an increasing drain of intermediates from the catabolic pathways (and hence an increasing production of surplus NADH) to support the higher levels of protein and RNA. The total flux into the TCA cycle through the reaction catalysed by pyruvate dehydro- 
Table 4. Cellular composition of $S$. cerevisiae as a function of the dilution rate in a glucose-limited culture

\begin{tabular}{|c|c|c|c|c|}
\hline \multirow[t]{2}{*}{ Metabolite } & \multicolumn{4}{|c|}{ Cellular content $(\%, w / w)$} \\
\hline & $D=0 \cdot 10 \mathrm{~h}^{-1}$ & $D=0 \cdot 20 \mathrm{~h}^{-1}$ & $D=0.30 h^{-1}$ & $D=0.40 \mathrm{~h}^{-1}$ \\
\hline Protein & $45 \cdot 0$ & $50 \cdot 0$ & $55 \cdot 5$ & $60 \cdot 1$ \\
\hline Glycogen & $8 \cdot 4$ & $4 \cdot 2$ & 0.6 & 0.0 \\
\hline Trehalose & $0 \cdot 8$ & $0 \cdot 2$ & $0 \cdot 0$ & $0 \cdot 0$ \\
\hline Mannan & $13 \cdot 1$ & $12 \cdot 9$ & $12 \cdot 0$ & $13 \cdot 3$ \\
\hline Other carbohydrates & $18 \cdot 4$ & $15 \cdot 4$ & $12 \cdot 6$ & 3.7 \\
\hline RNA & $6 \cdot 3$ & $8 \cdot 2$ & $10 \cdot 1$ & $12 \cdot 1$ \\
\hline DNA & 0.4 & 0.4 & 0.5 & $0 \cdot 6$ \\
\hline Free amino acids & $1 \cdot 1$ & $1 \cdot 3$ & $1 \cdot 1$ & $2 \cdot 0$ \\
\hline Lipid & $2 \cdot 9$ & $3 \cdot 0$ & $3 \cdot 8$ & $3 \cdot 4$ \\
\hline Ash & $5 \cdot 0$ & $5 \cdot 0$ & $5 \cdot 0$ & $5 \cdot 0$ \\
\hline Total & $101 \cdot 4$ & $100 \cdot 6$ & $101 \cdot 2$ & $100 \cdot 2$ \\
\hline
\end{tabular}

genase and the transport of oxaloacetate from the cytosol into the mitochondria decreases from 3.6 to $2 \cdot 6 \%$ of the glucose uptake when the specific growth rate increases from 0.1 to $0.3 \mathrm{~h}^{-1}$. This drop is almost exclusively due to the decrease in the succinate production with increasing specific growth rate and is only reflected in the influx of oxaloacetate to the mitochondria, while the flux through the reaction catalysed by pyruvate dehydrogenase is almost constant. A split in the TCA cycle into an oxidative (clockwise) and a reductive branch is observed at both specific growth rates. It should be noted that the reductive branch is thermodynamically feasible and has been proposed to operate in S. cerevisiae (Lupiañez et al., 1974; Machado et al., 1975). The reductive branch and the ADH I/ADH III shunt are two possible routes for oxidation of surplus $\mathrm{NADH}$ produced in the mitochondria by the oxidative TCA branch and in the synthesis of amino acids. It is seen that the flux through the reductive branch decreases to a very low level while the flux through the shunt increases slightly when the specific growth rate increases. This indicates that the ADH I/ADH III shunt is the primary route in the regeneration of $\mathrm{NAD}^{+}$in the mitochondria while the reductive branch is primarily involved in the formation of succinate.

The rates of malate and of cytosolic fumarate formation were not measured in the present study, but were calculated from the model assuming that the two compounds are secreted into the medium without being further metabolized. The calculated specific production rates correspond reasonably well with measurements of both these compounds in anaerobic, glucose-limited continuous cultures of $S$. cerevisiae CBS 8066 (Verduyn et al., 1990).

The specific production rate of ethanol was calculated by the model to be 0.0176 and $0.0551 \mathrm{C}-\mathrm{mol}$ (g dry weight $)^{-1} \mathrm{~h}^{-1}$ at $D=0 \cdot 1$ and $0.3 \mathrm{~h}^{-1}$, respectively. This corresponds to ethanol yields on glucose of $0.405 \mathrm{~g} \mathrm{~g}^{-1}$ at $D=0.1 \mathrm{~h}^{-1}$ and $0.406 \mathrm{~g} \mathrm{~g}^{-1}$ at $D=0.3 \mathrm{~h}^{-1}$, i.e. about
$6 \%$ higher than the measured yield of $0.381 \mathrm{~g} \mathrm{~g}^{-1}$ (Table 2). A possible explanation for this discrepancy is that more ethanol evaporates than accounted for (see Methods).

The metabolic flux model is an excellent tool for examining the presence and localization of reactions in the metabolism. This was tested by deleting the reaction catalysed by $\mathrm{ADH}$ III from the model, whereby the redox shunt across the mitochondrial membranes is no longer present. The calculated fluxes are shown in Fig. 4 (italic numbers). As the basis for the calculation the data from the dilution rate $0.3 \mathrm{~h}^{-1}$ was used. It is seen that the flux through the reductive branch of the TCA cycle increases when compared to the calculated fluxes at $D=0.3 \mathrm{~h}^{-1}$ where the redox shunt is included (bold numbers in Fig. 4), and that the branch also includes the reactions from succinate to 2-oxoglutarate. Since this last reaction (which is the sum of two reactions with succinyl-CoA as an intermediate) is thermodynamically favourable in the opposite direction $\left(\Delta G^{\circ}=-7 \cdot 2 \mathrm{~kJ}\right.$ $\mathrm{mol}^{-1}$ in the reaction from 2-oxoglutarate to succinylCoA), the calculated fluxes in the model without the reaction catalysed by ADH III are probably incorrect, and this indicates that the redox shunt has a role in the regulation of the redox level in the mitochondria. Similarly, the presence of an NADPH-dependent isocitrate dehydrogenase (IDP2) in the cytosol was tested since it has been proposed that this enzyme has an important role in the production of NADPH in this compartment (Bruinenberg, 1983). This was done by including the reaction in the model and calculating the fluxes using the data obtained at $D=0.3 \mathrm{~h}^{-1}$ (italic numbers in Fig. 5). It is seen that the presence of the reaction has a significant effect on the calculated fluxes. The origin of this effect is the occurrence of another redox shunt across the mitochondrial membrane where NADH is consumed in the mitochondria by the NADHdependent isocitrate dehydrogenase (IDH) leading to a substantial formation of isocitrate which is transported 

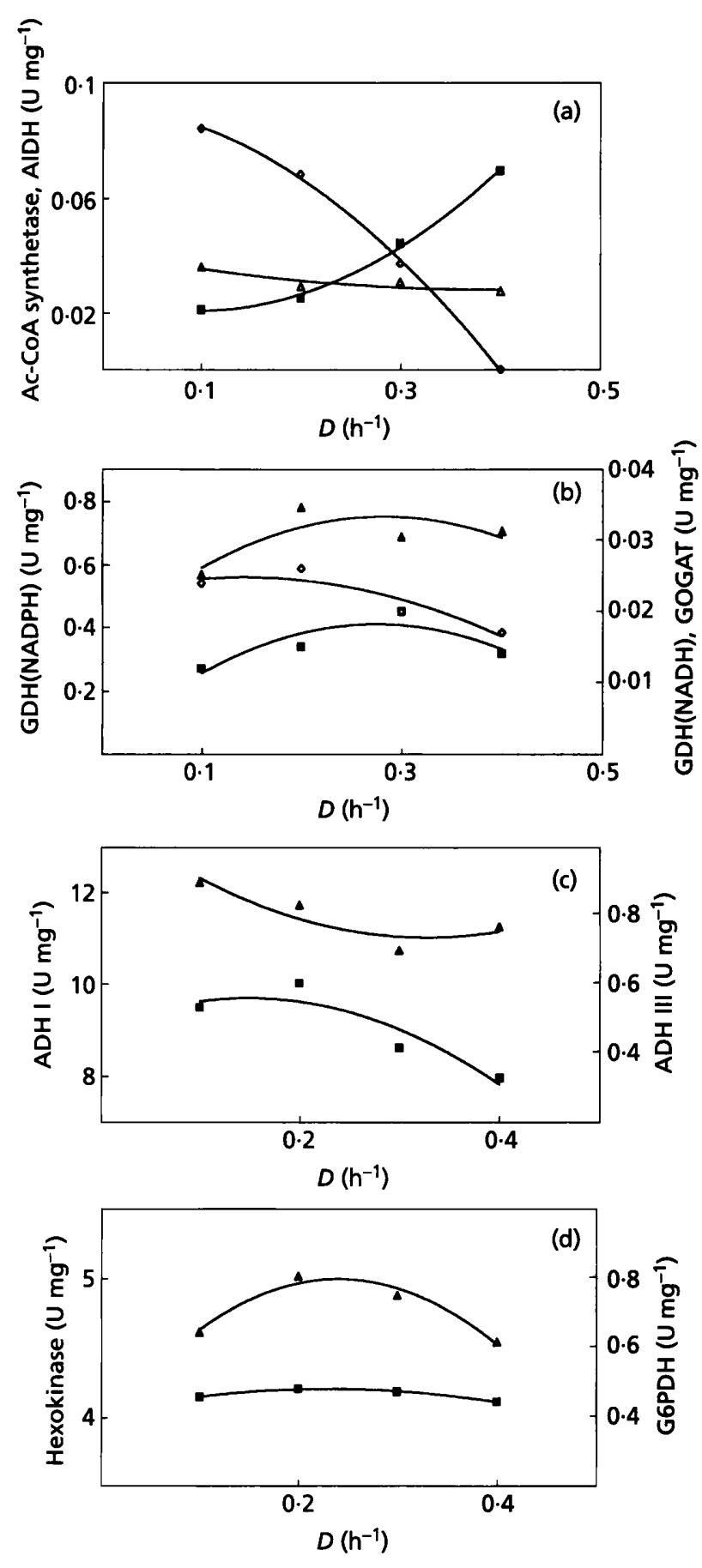

Fig. 2. In vitro specific enzyme activities as functions of dilution rate. (a) acetyl-CoA synthetase $(\boldsymbol{A})$ and $N A D(P)^{+}-$and NADP+dependent aldehyde dehydrogenase $(\bullet, \square)$; (b) NADH- and NADPH-dependent glutamate dehydrogenase $(\square, \Delta)$ and GOGAT ( ); (c) mitochondrial (ADH III) and cytosolic (ADH I) alcohol dehydrogenase $(\square, \Delta)$; (d) glucose-6-phosphate 1dehydrogenase $(\boldsymbol{G})$ and hexokinase $(\boldsymbol{\Delta})$.

to the cytosol and converted back to 2-oxoglutarate with an accompanying large production of NADPH in this compartment. In order to remove the pool of $\mathrm{NADPH}$ the model calculates negative fluxes through the PP pathway, and this is thermodynamically unfeasible since the reaction from glucose-6-phosphate to ribose-5-phosphate is practically irreversible $\left(\Delta G^{0}=\right.$ $-47.04 \mathrm{~kJ} \mathrm{~mol}^{-1}$ ). The high amount of NADH which is consumed when converting 2-oxoglutarate to isocitrate in the mitochondria is produced in the remaining part of the TCA cycle and by reversing the direction of the reaction catalysed by ADH III. The calculated flux pattern indicates that IDP2 is absent under the growth condition used in this study. Instead, the enzyme might play a role in the production of NADPH during growth on other carbon sources. This hypothesis is supported by a recent study where no activity of the enzyme could be detected when growing $S$. cerevisiae on glucose whereas the enzyme was active in cells grown on ethanol or glycerol (Loftus et al., 1994). It should also be noted that when using data obtained from dilution rates different from $D=0.3 \mathrm{~h}^{-1}$, most reasonable results are obtained by including the reaction catalysed by $\mathrm{ADH}$ III and excluding the reaction catalysed by IDP2.

\section{Sensitivity analysis}

To determine the sensitivity of the flux calculations towards measurement errors a sensitivity analysis was carried out as described above. In the analysis, the RSD values described in Methods were used. The analysis showed that accurate measurements of the specific glucose uptake rate and the specific production rates of ethanol, glycerol, $\mathrm{CO}_{2}$ and protein are critical for calculating the correct fluxes while an error in the measurement of any other compound only leads to incorrect fluxes through the last two or three reactions at the end of the biosynthesis of the given compound. The measurement of the ethanol concentration in the medium is very accurate, but systematic errors arise due to evaporation of the compound from the bioreactor. As previously discussed the correction procedure by which evaporated ethanol is captured in liquid $\mathrm{N}_{2}$ does not recover all ethanol lost from the reactor. Therefore, ethanol was not included in the vector of measured rates, and the calculated ethanol flux can possibly be used to improve the correction procedure. The measurements of $\mathrm{CO}_{2}$ and glucose are critical for the correct calculation of the fluxes through the PP and the EMP pathway (a relative error of $0.6 \%$ leads to relative errors of $1.4 \%$ in the fluxes), in the TCA cycle (relative errors of 3.0 to $6.0 \%$ ) and to ethanol, RNA and DNA (relative errors of 2.4 to $3.6 \%$ ). The glycerol measurement has a significant effect on the fluxes in certain mitochondrial reactions (in most TCA cycle reactions one obtains relative deviations from 3.0 to $6.0 \%$ while flux 18 and 37 are particularly sensitive with relative errors of respectively 18.0 and $9.0 \%$ ). Similarly, the error of $2.5 \%$ in the protein measurement leads to a $1.2 \%$ change in the fluxes through the PP pathway and a $5.0 \%$ change in the fluxes 17 and 18 . It should be noted that the protein content increases by far more than the $2.5 \%$ used in the sensitivity analysis when the specific growth rate is increased from 0.1 to $0.3 \mathrm{~h}^{-1}$. This means that an assumption of a constant protein content under different 


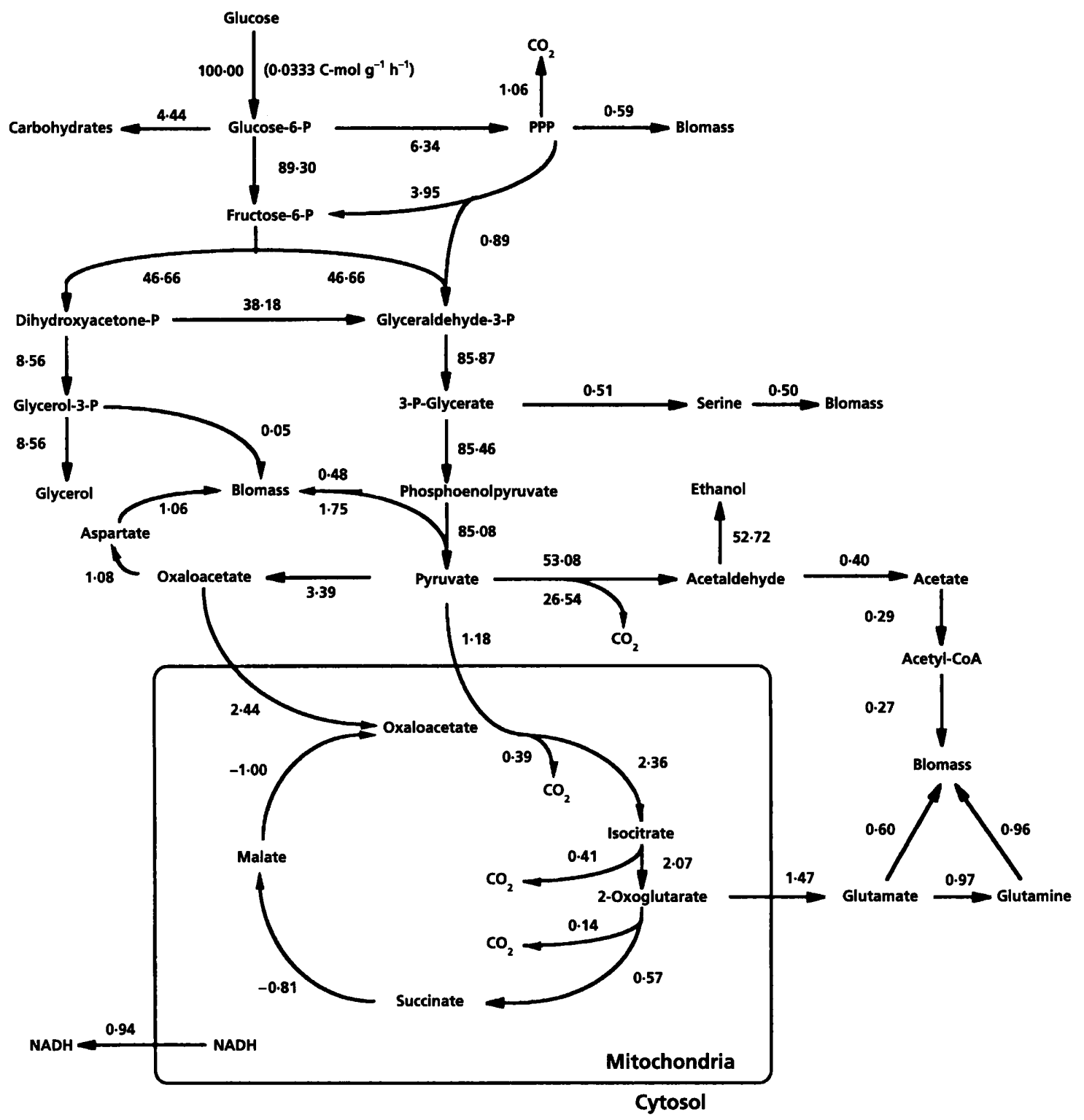

Fig. 3. Flux distribution at $D=0.1 \mathrm{~h}^{-1}$. All fluxes are in the direction of the arrows. A negative value means that the flux is in the direction opposite to the arrow. The flux from mitochondrial NADH to cytosolic NADH is a result of the ADH $/$ / $A D H$ III shuttle. The fluxes are normalized with respect to the specific glucose uptake. The measured specific glucose uptake is shown next to the normalized value.

growth conditions leads to a significant error in the calculation of the flux distributions. This might also be true for other macromolecules under aerobic conditions where the amount of carbon going from glucose to biomass is fivefold higher.

\section{Conclusions}

In conclusion, three obvious applications exist for the MFA :

(1) Data from physiological studies can easily be analysed and information concerning intracellular flux distributions under various growth conditions can be evaluated. In the present study, calculations of the split between the PP and the EMP pathways, and of the flux into the mitochondria at various growth rates, were used to illustrate how further insight into the growth physiology may be obtained through flux analysis.

(2) It is possible to test for the presence or absence of single reactions or whole pathways in the metabolism. This application was demonstrated with the reactions catalysed by $\mathrm{ADH}$ localized in the mitochondria and isocitrate dehydrogenase localized in the cytosol. It was concluded that during anaerobic growth $\mathrm{ADH}$ III together with the reductive branch of the TCA cycle 


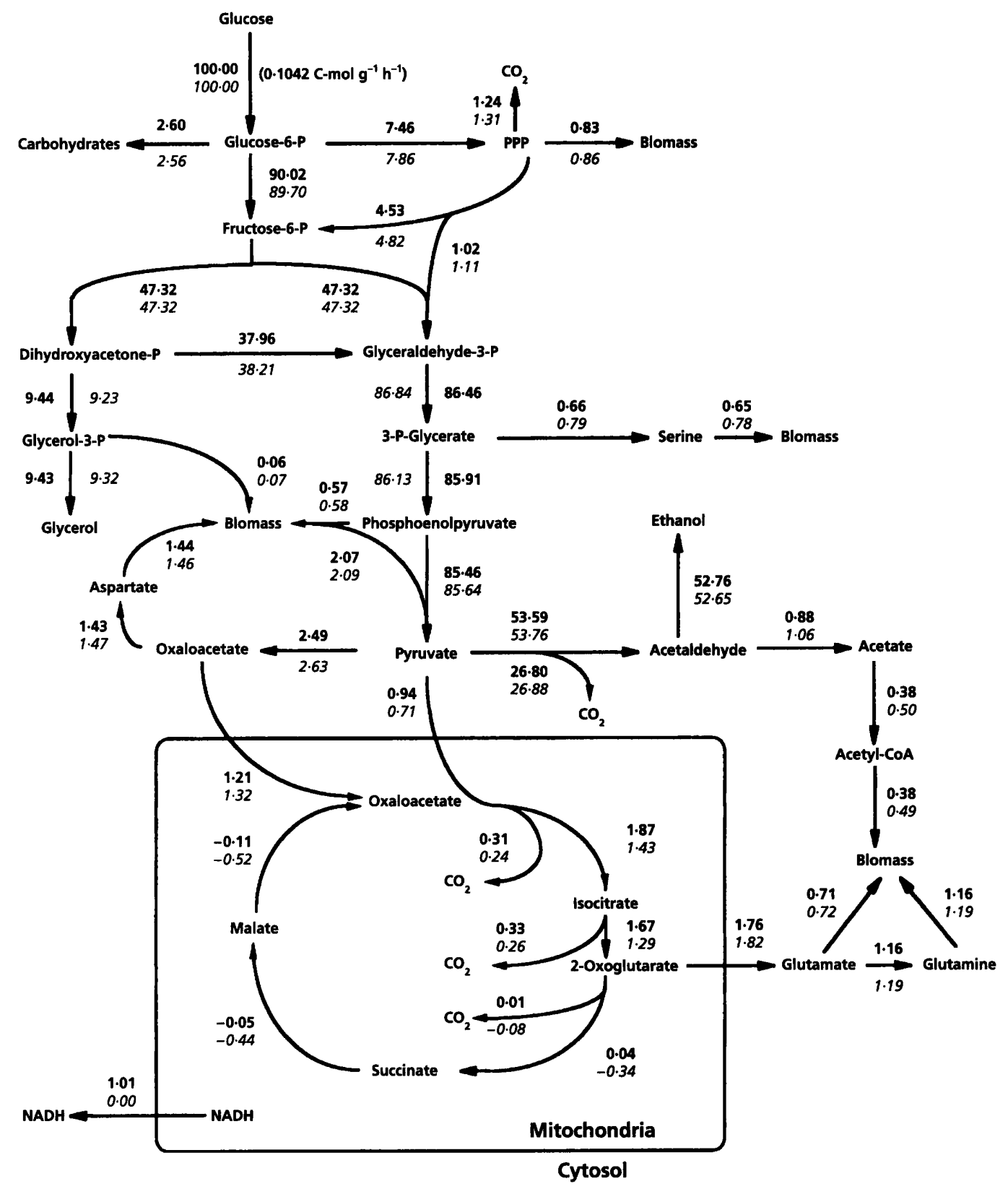

Fig. 4. Flux distribution at $D=0.3 \mathrm{~h}^{-1}$ calculated with the basic stoichiometric model (bold numbers) and with a stoichiometric model without the reaction catalysed by ADH III (italic numbers), respectively. See also legend to Fig. 3 .

regenerates the mitochondrial pool of $\mathrm{NAD}^{+}$that is consumed in the synthesis of amino acids and compounds in the TCA cycle. It was also shown that IDP2 probably does not serve as a source of NADPH in the cytosol during anaerobic growth on glucose. The consequences of deletions or insertions of pathways in the central metabolism through genetic engineering can be evaluated in the same way. The MFA is consequently a simple and powerful tool when deciding a strategy for metabolic engineering of a given micro-organism.

(3) The MFA can in general be applied to calculate yields of compounds which are not measured if the degrees of freedom in the model exceeds the number necessary for determining the fluxes. Here the fluxes of malate and cytosolic fumarate were calculated and a possible systematic error in the ethanol measurement was indicated.

To calculate correct fluxes it is necessary to have precise measurements of the specific consumption rates of the substrates and of the specific production rates of the products which form the basis for the flux analysis. In this work, the physiological studies were carried out using steady state continuous cultures where the rates were determined from a single but well-established 


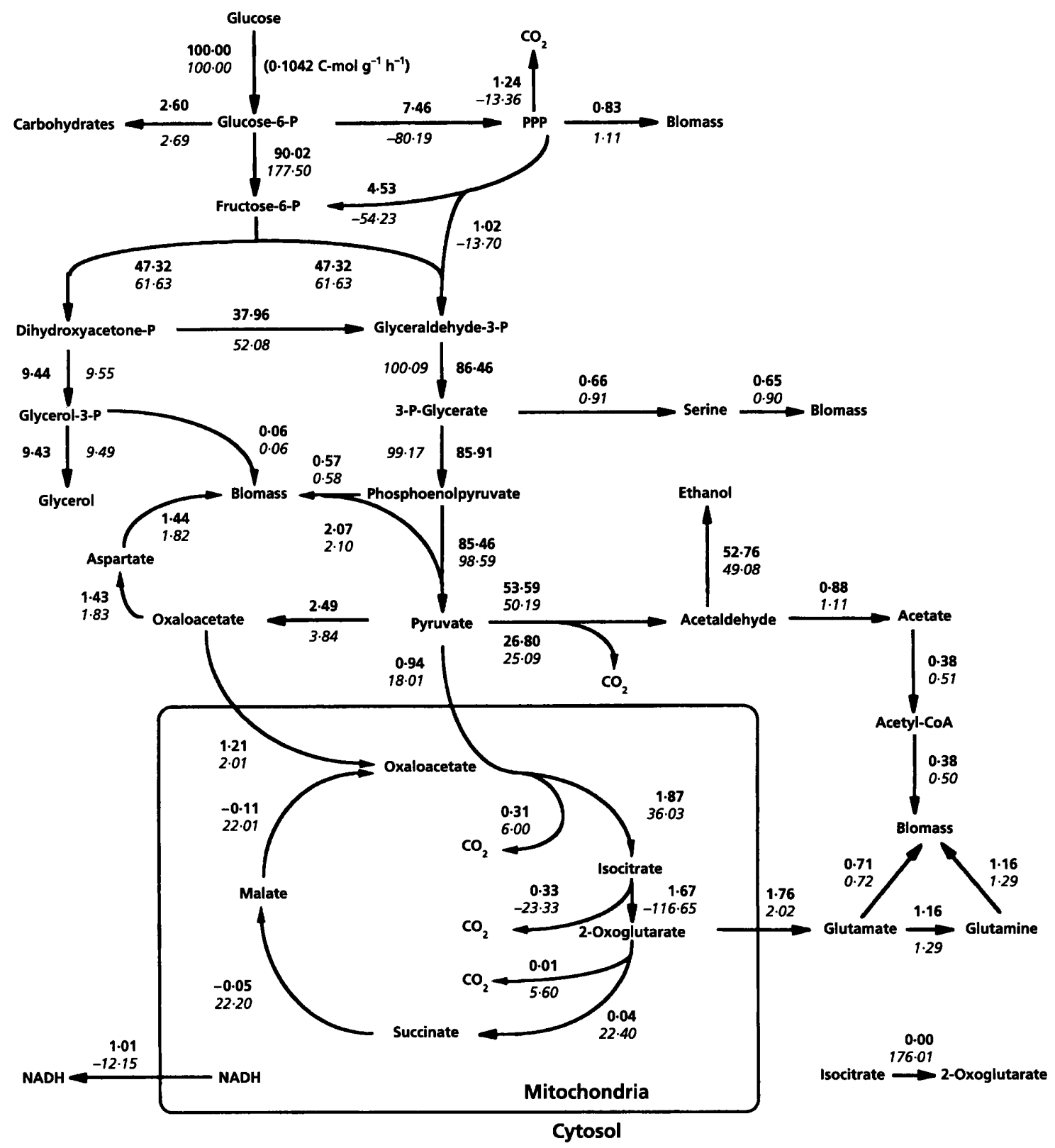

Fig. 5. Flux distribution at $D=0.3 \mathrm{~h}^{-1}$ calculated with the basic stoichiometric model (bold numbers) and with a stoichiometric model including the reaction catalysed by IDP2 (italic numbers), respectively. See also legend to Fig. 3.

measurement of the substrates and the products at any given specific growth rate. Furthermore, carbon and redox balances of the measurements were set up leading to the conclusion that no major product was ignored in the flux analysis. When using other cultivation strategies, e.g. batch or fed batch cultivations, estimation of the specific rates to be used for the flux calculations is difficult, since it requires information on the time derivatives of the concentrations in the medium.

In the evaluation of the outcome of MFA, a sensitivity analysis determines the influence of each measurement on the calculations, and this creates a quantitative basis on which the required precision of the measurements can be determined. In this work a sensitivity analysis showed that the measurement of the specific consumption rate of glucose and the specific production rates of ethanol, glycerol, protein and $\mathrm{CO}_{2}$ were important for the calculation of the correct fluxes. Ethanol was, however, not included in the stoichiometric matrix since there might be a small, but systematic, error in its determination. The accuracy in the measurements of the remaining four compounds was sufficient to ensure that accurate fluxes were calculated - and hence that the calculated ethanol flux might be more accurate than the measured flux. 


\section{REFERENCES}

Aiba, S. \& Matsuoka, M. (1979). Identification of metabolic model: citrate production from glucose by Candida lipolytica. Biotechnol Bioeng 21, 1373-1386.

Andreasen, A. A. \& Stier, T. J. B. (1953). Anaerobic nutrition of Saccharomyces cerevisiae. I. Ergosterol requirement for the growth in a defined medium. J Cell Comp Physiol 41, 23-36.

Bailey, J. E. (1991). Towards a science of metabolic engineering. Science 252, 1668-1675.

Barkholt, V. \& Jensen, A. L. (1989). Amino acid analysis: determination of cysteine plus half-cysteine in proteins after hydrochloric acid hydrolysis with a disulfide compound as additive. Anal Biochem 177, 318-322.

Benthin, S., Nielsen, J. \& Villadsen, J. (1991). A simple and reliable method for the determination of cellular RNA content. Biotechnol Tech 5, 39-42.

Benthin, S., Schulze, U., Nielsen, J. \& Villadsen, J. (1994). Growth energetics of Lactococcus cremoris FD1 during energy-, carbonand nitrogen-limitation in steady state and transient cultures. Chem Eng Sci 49, 589-609.

van der Berg, M. A. \& Steensma, H. Y. (1995). ACS2, a Saccharamyces cerevisiae gene encoding acetyl coenzyme A synthetase, is essential for growth on glucose. Abstracts of the European Research Conference on Control of Metabolic Flux: Metabolic Pathway Engineering in Yeast. Granada, Spain.

Bisson, L. F. \& Fraenkel, D. G. (1983). Transport of 6-deoxyglucose in Saccharomyces cerevisiae. J Bacteriol 155, 995-1000.

Boulton, C. A. \& Ratledge, C. (1981). Correlation of lipid accumulation in yeasts with possession of ATP:citrate lyase. $J$ Gen Microbiol 127, 169-176.

Breton, A. \& Surdin-Kerjan, Y. (1977). Sulfate uptake in Saccharomyces cerevisiae: biochemical and genetic study. J Bacteriol 132, 224-232.

Bruinenberg, P. M. (1983). The $N A D(P) H$ redox couple in yeast metabolism: fundamental and applied aspects. $\mathrm{PhD}$ thesis, Technical University of Delft.

Bruinenberg, P. M., van Dijken, J. P. \& Scheffers, W. A. (1983). An enzymic analysis of NADPH production and consumption in Candida utilis. J Gen Microbiol 129, 965-971.

Cartwright, C. P., Rose, A. H., Calderbank, J. \& Keenan, M. H. J. (1989). Solute transport. In The Yeasts, vol. 3, Metabolism and Physiology of Yeasts, pp. 5-56. Edited by A. H. Rose \& J. S. Harrison. London: Academic Press.

Christensen, L. H., Nielsen, J. \& Villadsen, J. (1991). Monitoring of substrates and products during fed-batch penicillin fermentations on complex media. Anal Chim Acta 249, 123-136.

Christensen, L. H., Schulze, U., Nielsen, J. \& Villadsen, J. (1995). Acoustic off-gas analyser for bioreactors: precision, accuracy and dynamics of detection. Chem Eng Sci 50, 2601-2610.

Ciriacy, M. (1979). Isolation and characterisation of further cisand trans-acting regulatory elements in the synthesis of glucoserepressible alcohol dehydrogenase (ADH II) in Saccharomyces cerevisiae. Mol Gen Genet 176, 427-431.

Cockburn, M., Earnshaw, P. \& Eddy, A. A. (1975). The stoichiometry of the absorption of protons with phosphate and Lglutamate by yeasts of the genus Saccharomyces. Biochem J 146, 705 .

Cooper, T. G. (1982). Nitrogen metabolism in Saccharomyces cerevisiae. In The Molecular Biology of the Yeast Saccharomyces: Metabolism and Gene Expression, pp. 39-99. Edited by J. N.
Strathern, E. W. Jones \& J. R. Broach. Cold Spring Harbor, NY: Cold Spring Harbor Laboratory.

Cupp, J. R. \& McAlister-Henn, L. (1991). NAD ${ }^{+}$-dependent isocitrate dehydrogenase. Cloning, nucleotide sequence, and disruption of the IDH2 gene from Saccharomyces cerevisiae. J Biol Chem 266, 22199-22205.

Cupp, J. R. \& McAlister-Henn, L. (1992). Cloning and characterization of the gene encoding the idh 1 subunit of $\mathrm{NAD}^{+}$ dependent isocitrate dehydrogenase from Saccharomyces cerevisiae. J Biol Chem 267, 16417-16423.

Danielsson, B. \& Moseley, S. B. (1986). Theory and applications of calorimetric sensors. In Biosensors: Fundamentals and Applications, pp. 575-595. Edited by A. P. F. Turner, I. Karube \& G. Wilson. Oxford: Oxford University Press.

Farkas, V. (1989). Polysaccharide metabolism. In The Yeasts, vol. 3, Metabolism and Physiology of Yeasts, pp. 317-366. Edited by A. H. Rose \& J. S. Harrison. London: Academic Press.

Frenkel, E. P. \& Kitchens, R. L. (1977). Purification and properties of acetyl coenzyme A synthetase from baker's yeast. J Biol Chem 252, 504-507.

Fritz, I. B. \& Schultz, S. K. (1965). Carnitine acetyltransferase. $J$ Biol Chem 240, 2188.

Furukawa, K., Heinzle, E. \& Dunn, I. J. (1983). Influence of oxygen on growth of Saccharomyces cerevisiae in continuous culture. Biotechnol Bioeng 25, 2293-2317.

Gancedo, C., Gancedo, J. M. \& Sols, A. (1968). Glycerol metabolism in yeast. Pathways of utilization and production. Eur $J$ Biochem 5, 168-172.

Gancedo, C. \& Serrano, R. (1989). Energy yielding metabolism. In The Yeasts, vol. 3, Metabolism and Physiology of Yeasts, pp. 205-259. Edited by A. H. Rose \& J. S. Harrison. London: Academic Press.

Haarasilta, S. \& Taskinen, L. (1977). Location of the three enzymes of gluconeogenesis in baker's yeast. Arch Microbiol 113, 159-161.

Haselbeck, R. J. \& McAlister-Henn, L. (1991). Isolation, nucleotide sequence, and disruption of the Saccharomyces cerevisiae gene encoding mitochondrial $\mathrm{NADP}(\mathrm{H})$-specific isocitrate dehydrogenase. J Biol Chem 266, 2339-2345.

Herbert, D., Phipps, P. J. \& Strange,R. E. (1971). Chemical analysis of microbial cells. Methods Microbiol 5B, 209-344.

Holmes, A. R., Collins, A., Farnden, K. J. F. \& Shepherd, M. G. (1989). Ammonia assimilation by Candida albicans and other yeasts: evidence for the activity of glutamate synthase. $J$ Gen Microbiol 135, 1423-1430.

Holmes, A. R., McNaughton, G. S., More, R. D. \& Shepherd, M. G. (1991). Ammonium assimilation by Candida albicans and other yeasts: a ${ }^{13} \mathrm{~N}$ isotope study. Can J Microbiol 37, 226-232.

von Jagow, G. \& Klingenberg, M. (1970). Pathways of hydrogen in mitochondria of Saccharomyces carlsbergensis. Eur J Biochem $12,583-592$.

Jones, E. W. \& Fink, G. R. (1982). Regulation of amino acid and nucleotide biosynthesis in yeast. In The Molecular Biology of the Yeast Saccharomyces: Metabolism and Gene Expression, pp. 181-299. Edited by J. N. Strathern, E. W. Jones \& J. R. Broach. Cold Spring Harbor, NY: Cold Spring Harbor Laboratory.

Jones, P. J. \& Greenfield, P. F. (1982). Effect of carbon dioxide on yeast growth and fermentation. Enzyme Microb Technol 4, 210-223.

Jones, R. P. (1989). Biological principles for the effects of ethanol. Enzyme Microb Technol 11, 130-153. 
Jørgensen, H., Nielsen, J., Villadsen, J. \& Møllgaard, H. (1995). Metabolic flux distribution in Penicillium chrysogenum during fed-batch cultivations. Biotechnol Bioeng 46, 117-131.

Keys, D. A. \& McAlister-Henn, L (1990). Subunit structure, expression, and function of $\mathrm{NAD}(\mathrm{H})$-specific isocitrate dehydrogenase in Saccharomyces cerevisiae. J Bacteriol 172, 4280-4287.

Klein, H. P. \& Jahnkle, L. (1979). Effects of aeration on formation and localizations of acetyl coenzyme A synthetases of Saccharomyces cerevisiae. J Bacteriol 137, 179-184.

Kohlhaw, G. B. \& Tan-Wilson, A. (1977). Carnitine acyltransferase: candidate for the transfer of acetyl groups through the mitochondrial membrane of yeast. J Bacteriol 129, 1159-1161.

Krämer, R. \& Palmieri, F. (1992). Metabolite carriers in mitochondria. In Molecular Mechanisms in Bioenergetics, pp. 359-384. Edited by L. Ernster. Amsterdam: Elsevier.

Küenzi, M. T. \& Fiechter, A. (1972). Regulation of carbohydrate composition of Saccharomyces cerevisiae under growth limitation. Arch Microbiol 84, 254-265.

LaNoue, K. F. \& Schoolwerth, A. C. (1979). Metabolite transport in mitochondria. Annu Rev Biochem 48, 871-922.

Libudzisz, Z., Mansfels, B., Kacki, E. \& Obermann, H. (1986). Optimization of the cultivation medium composition for lactic acid bacteria. Milchwiss 41, 625-629.

Lidén, G., Persson, A., Gustafsson, L. \& Niklasson, C. (1995). Energetics and product formation by Saccharomyces cerevisiae grown in anaerobic chemostats under nitrogen limitation. Appl Microbiol Biotechnol 43, 1034-1038.

Loftus, T. M, Hall, L. V., Anderson, S. L. \& McAlister-Henn, L. (1994). Isolation, characterization, and disruption of the yeast gene encoding cytosolic NADP-specific isocitrate dehydrogenase. Biochemistry 33, 9661-9667.

Lupiañez, J. A., Machado, A., de Castro, I. N. \& Mayor, F. (1974). Succinic acid production by yeast grown under different hypoxic conditions. Mol Cell Biochem 3, 113-116.

Lutsdorf, U. \& Megnet, R. (1968). Multiple forms of alcohol dehydrogenase in Saccharomyces cerevisiae. I. Physiological control of ADH-2 and properties of ADH-2 and ADH-4. Arch Biochem Biophys 126, 933-944.

McClellan, C. J. \& Bisson, L. F. (1988). Glucose uptake in Saccharomyces cerevisiae grown under anaerobic conditions: effect of null mutations in hexokinase and glucokinase structural genes. J Bacteriol 170, 5396-5400.

Machado, A., de Castro, I. N. \& Mayor, F. (1975). Isocitrate dehydrogenase and oxoglutarate dehydrogenase activities of baker's yeast grown in a variety of hypoxic conditions. Mol Cell Biochem 6, 93-100.

Malaney, G. W., Tanner, R. D., Shipp, E. A. \& Slonim, A. E. (1989). The effect of high sodium chloride in the growth medium on the content of the essential amino acids in the intracellular pool in baker's yeast during aerobic fermentation of glucose. Food Microbiol 6, 1-6.

Mitchell, A. P. \& Magasanik, P. (1983). Purification and properties of glutamine synthetase from Saccharomyces cerevisiae. J Biol Chem 258, 119-125.

Nielsen, J. \& Villadsen, J. (1994). Bioreaction Engineering Principles. New York: Plenum.

Oura, E. (1972). The effect of aeration rate on the growth energetics and biochemical composition of baker's yeast. $\mathrm{PhD}$ thesis, University of Helsinki.

Oura, E. (1977). Reaction products of yeast fermentations. Process Biochem 12, 19-21; 35.
Papoutsakis, E. T. (1984). Equations and calculations for fermentations of butyric acid bacteria. Biotechnol Bioeng 26, 174-187.

Perkins, M., Haslam, J. M. \& Linnane, A. W. (1973). Biogenesis of mitochondria. The effects of physiological and genetic manipulations of Saccharomyces cerevisiae on the mitochondrial transport systems for the tricarboxylate-cycle anions. Biochem J 134, 923-934.

Pirt, S. J. (1965). The maintenance energy of bacteria in growing cultures. Proc R Soc London Ser B 163, 224-231.

Postma, E., Verduyn, C., Scheffers, W. A. \& van Dijken, J. P. (1989). Enzyme analysis of the crabtree effect in glucose-limited chemostat cultures of Saccharomyces cerevisiae. Appl Environ Microbiol 53, 468-477.

Rattray, J. B. M. (1988). Yeast. In Microbial Lipid, vol. 1, pp. 555-685. Edited by C. Ratledge \& S. G. Wilkinson. London: Academic Press.

de Robichon-Szulmajster, H. \& Surdin-Kerjan, Y. (1971). Nucleic acid and protein synthesis in yeast: regulation of synthesis and activity. In The Yeasts, vol. 2, pp. 335-418. Edited by A. H. Rose \& J. S. Harrison. London: Academic Press.

Roomans, G. M., Kuypers, G. A. J., Theuvent, A. P. R. \& BorstPauwels, G. W. F. H. (1979). Kinetics of sulfate uptake by yeast. Biochem Biophys Acta 551, 197-206.

Roon, R. J., Even, H. L., Dunlop, P. \& Larimore, F. L. (1975). Methylamine and ammonia transport in Saccharomyces cerevisiae. J Bacteriol 122, 502-509.

Schatzmann, H. (1975). Anaerobes Wachstum von Saccharomyces cerevisiae. Regulatorische Aspekte des glycolytischen und respirativen Stoffwechsels. PhD thesis, ETH Zurich.

Schulze, U. (1995). Anaerobic physiology of Saccharomyces cerevisiae. PhD thesis, Technical University of Denmark.

Schulze, U., Larsen, M. E. \& Villadsen, J. (1995). Determination of intracellular trehalose and glycogen in Saccharomyces cerevisiae. Anal Biochem 228, 143-149.

Seegmiller, J. E. (1955). TPN-linked acetaldehyde dehydrogenase from yeast. Methods Enzymol 1, 511-514.

Sols, A., Gancedo, C. \& Delafuente, G. (1971). Energy yielding metabolism in yeast. In The Yeasts, vol. 2, pp. 271-307. Edited by A. H. Rose \& J. S. Harrison. London: Academic Press

Stanley, G. A. \& Pamment, N. B. (1993). Transport and intracellular accumulation of acetaldehyde in Saccharomyces cerevisiae. Biotechnol Bioeng 42, 24-29.

Stephanopoulos, G. \& Sinskey, A. J. (1993). Metabolic engineering - methodologies and future prospects. Trends Biotechnol 11, 392-396.

Stephanopoulos, G. \& Vallino, J. J. (1991). Network rigidity and metabolic engineering in metabolite overproduction. Science 252, 1675-1681.

Stryer, L. (1988). Biochemistry, 3rd edn. New York: Freeman.

Tamaki, N. \& Hama, T. (1982). Aldehyde dehydrogenase from baker's yeast. Methods Enzymol 89, 469-470.

Tuite, M. F. (1989). Protein synthesis. In The Yeasts, vol. 3, Metabolism and Physiology of Yeasts, pp. 161-204. Edited by A. H. Rose \& J. S. Harrison. London: Academic Press.

Vallino, J. J. \& Stephanopoulos, G. (1990). Flux determinations in cellular bioreaction networks: applications to lysine fermentations. In Frontiers in Bioprocessing, pp. 205-219. Edited by S. K. Sikdar, M. Bier \& P. Todd. Boca Raton, FL: CRC Press.

Vallino, J. J. \& Stephanopoulos, G. (1993). Metabolix flux distributions in Corynebacterium glutamicum during growth and lysine overproduction. Biotechnol Bioeng 41, 633-646. 
Verduyn, C., Postma, E., Scheffers, W. A. \& van Dijken, J.P. (1990). Physiology of Saccharomyces cerevisiae in anaerobic glucose-limited chemostat cultures. J Gen Microbiol 136, 395-403.

Verduyn, C., Postma, E., Scheffers, W. A. \& van Dijken, J. P. (1992). Effect of benzoic acid on metabolic fluxes in yeast: a continuous culture study on the regulation of respiration and alcoholic fermentation. Yeast 8, 501-517.

Viegas, C. F., Rose, M. F., Sá-Correia, I. \& Novais, J. M. (1989). Inhibition of yeast growth by octanoic and decanoic acids produced during ethanolic fermentations. Appl Environ Microbiol 55, 21-28.

Visser, W., Van der Baan, A. A., Batenburg-van der Vegte, W., Scheffers, W. A., Krämer, R. \& van Dijken, J. P. (1994). Involvement of mitochondria in the assimilatory metabolism of Saccharomyces cerevisiae. Microbiology 140, 3039-3046.

Waldron, C. (1977). Synthesis of ribosomal and transfer ribonucleic acids in yeast during a nutritional shift-up. $J$ Gen Microbiol 98, 215-221.

Wales, D. S., Cartledge, T. G. \& LLoyd, D. (1980). Effect of glucose repression and anaerobiosis on the activities and subcellular distribution of tricarboxylic acid cycle and associated enzymes in Saccharomyces carlsbergensis. J Gen Microbiol 116, 93-98.

Watson, M. R. (1976). Amino-acid pool composition of Saccharomyces cerevisiae as a function of growth rate and amino acid nitrogen source. J Gen Microbiol 96, 263-268.

\section{APPENDIX A: Compounds and reactions in the stoichiometric matrix}

\section{Compounds}

1. Acetate

2. Ethanol

3. Glycerol

4. Pyruvate

5. Succinate

6. RNA

7. $\mathrm{CO}_{2}$

8. Glucose

9. $\mathrm{NH}_{4}^{+}$(extracellular)

10. Carbohydrate

11. DNA

12. Protein

13. Lipid

14. Sulphate

15. 5-AICAR

16. 2-Oxoglutarate

17. 3-Phosphoglycerate

18. Methyl-THF

19. Acetaldehyde

20. Acetyl-CoA

21. $\mathrm{NH}_{4}^{+}$(intracellular)

22. Aspartate

23. Dihydroxyacetonephosphate

24. Erythrose-4-phosphate $\left(\mathrm{CH}_{4 / 7} \mathrm{OP}_{1 / 4}\right)$
25. Fructose-6-phosphate

26. Malate

27. Glucose-6-phosphate

28. Glutamate

29. Glutamine

30. Glyceraldehyde-3phosphate

31. Glycerol-3-phosphate

32. $\mathrm{NADPH}_{\mathrm{mit}}$

33. $\mathrm{NADPH}_{\mathrm{cyt}}$

34. $\mathrm{NADH}_{\mathrm{mit}}$

35. $\mathrm{NADH}_{\text {cyt }}$

36. Oxaloacetate mit

37. Phosphoenolpyruvate

38. Ribose-5-phosphate

39. Serine

40. ATP

41. Isocitrate

42. Oxaloacetate ${ }_{\text {cyt }}$

43. Fumarate ${ }_{\text {cyt }}$
$\left(\mathrm{CH}_{11 / 6} \mathrm{OP}_{1 / 6}\right)$

$\left(\mathrm{CHO}_{3 / 2}\right)$

$\left(\mathrm{CH}_{11 / 6} \mathrm{OP}_{1 / 6}\right)$

$\left(\mathrm{CH}_{5 / 8} \mathrm{O}_{4 / 5} \mathrm{~N}_{1 / 5}\right)$

$\left(\mathrm{CH}_{2} \mathrm{O}_{3 / 5} \mathrm{~N}_{2 / 5}\right)$

$\left(\mathrm{CH}_{5 / 3} \mathrm{OP}_{1 / 3}\right)$

$\left(\mathrm{CH}_{7 / 3} \mathrm{OP}_{1 / 3}\right)$

(' $\mathrm{H}$ ')

(' $\mathrm{H}$ ')

(' $\mathrm{H}$ ')

(' $\mathrm{H}$ ')

$\left(\mathrm{CH}_{1 / 2} \mathrm{O}_{5 / 4}\right)$

$\left(\mathrm{CH}_{2 / 3} \mathrm{OP}_{1 / 3}\right)$

$\left(\mathrm{CH}_{9 / 5} \mathrm{OP}_{1 / 5}\right)$

$\left(\mathrm{CH}_{7 / 3} \mathrm{ON}_{1 / 3}\right)$

$\left(\mathrm{CH}_{5 / 6} \mathrm{O}_{7 / 6}\right)$

$\left(\mathrm{CH}_{1 / 2} \mathrm{O}_{5 / 4}\right)$

$\left(\mathrm{CH}_{1 / 2} \mathrm{O}\right)$

\section{Reactions}

Compounds in bold letters are included in the stoichiometric matrix.

1. Glucose $+1 / 6 \mathrm{ATP} \rightarrow$ Glucose-6-P $+1 / 6 \mathrm{ADP}+$ $1 / 6 \mathrm{H}^{+}$

2. Glucose-6-P $\rightarrow$ Fructose-6-P

3. Fructose-6-P $+1 / 6$ ATP $\rightarrow 1 / 2$ Glyceraldehyde + $1 / 2$ Dihydroxyacetone-P $+1 / 6 \mathrm{ADP}+1 / 6 \mathrm{H}^{+}$

4. Dihydroxyacetone-P $\rightarrow$ Glyceraldehyde-3-P

5. Glyceraldehyde-3-P $+1 / 3 \mathrm{NAD}^{+}+1 / 3 \mathrm{ADP}+1 / 3 \mathrm{P}_{\mathrm{i}}$ $\rightarrow$ 3-P-glycerate $+1 / 3 \mathrm{ATP}+1 / 3 \mathrm{NADH}_{\text {cyt }}+$ $1 / 3 \mathrm{H}^{+}$

6. 3-P-Glycerate $\rightarrow$ Phosphoenolpyruvate $+1 / 3 \mathrm{H}_{2} \mathrm{O}$

7. Phosphoenolpyruvate $+1 / 3 \mathrm{ADP}+1 / 3 \mathrm{H}^{+} \rightarrow$ Pyruvate $+1 / 3$ ATP

8. Pyruvate $+1 / 3 \mathrm{H}^{+} \rightarrow 2 / 3$ Acetaldehyde $+1 / 3 \mathrm{CO}_{2}$

9. Acetaldehyde $+1 / 2 \mathrm{NADH}_{\text {cyt }}+1 / 2 \mathrm{H}^{+} \rightarrow$ Ethanol + 1/2NAD ${ }^{+}$

10. Acetaldehyde $+1 / 2 \mathrm{NADP}^{+}+1 / 2 \mathrm{H}_{2} \mathrm{O} \rightarrow$ Acetate$+1 / 2 \mathrm{NADPH}_{\mathrm{cyt}}+1 / 2 \mathrm{H}^{+}$

11. Dihydroxyacetone-P $+1 / 3 \mathrm{NADH}_{\text {cyt }}+1 / 3 \mathrm{H}^{+} \rightarrow$ Glycerol-3-P + 1/3NAD .

12. Glycerol-3-P $+1 / 3 \mathrm{H}^{+} \rightarrow$ Glycerol $+1 / 3 \mathrm{P}_{\mathrm{i}}$

13. Glucose-6-P $+1 / 3 \mathrm{NADP}^{+}+1 / 2 \mathrm{H}_{2} \mathrm{O} \rightarrow$ $5 / 6$ Ribose-5-P $+1 / 3 \mathrm{NADPH}_{\text {cyt }}+$ $1 / 3 \mathrm{H}^{+}+1 / 6 \mathrm{CO}_{2}$

14. Ribose-5-P $\rightarrow 2 / 5$ Erythrose-4-P $+3 / 5$ Fructose-6-P

15. 5/9Ribose-5-P+4/9Erythrose-4-P $\rightarrow$ 6/9Fructose6-P + 3/9Glyceraldehyde-3-P

16. $3 / 7$ Pyruvate $+4 / 7 \mathrm{Oxaloacetate} \mathrm{e}_{\text {mit }}+1 / 7 \mathrm{NAD}^{+}+$ $1 / 7 \mathrm{H}_{2} \mathrm{O} \rightarrow 6 / 7$ Isocitrate $+1 / 7 \mathrm{CO}_{2}+$ $1 / 7 \mathrm{H}^{+}+1 / 7 \mathrm{NADH}_{\text {mit }}$

17. Isocitrate $+1 / 6 \mathrm{NAD}^{+} \rightarrow 5 / 62$-Oxoglutarate + $1 / 6 \mathrm{CO}_{2}+1 / 6 \mathrm{NADH}_{\text {mit }}$

18. 2-Oxoglutarate $+1 / 5 \mathrm{NAD}^{+}+1 / 5 \mathrm{ADP}+1 / 5 \mathrm{P}_{\mathrm{i}}+$ $1 / 5 \mathrm{H}_{2} \mathrm{O} \rightarrow 4 / 5$ Succinate $+1 / 5 \mathrm{ATP}+$ $1 / 5 \mathrm{CO}_{2}+1 / 5 \mathrm{NADH}_{\text {mit }}+1 / 5 \mathrm{H}^{+}$

19. Succinate $+1 / 4 \mathrm{FAD} \rightarrow$ Malate $+1 / 4 \mathrm{FADH} 2$ 
20. Malate $+1 / 4 \mathrm{H}_{2} \mathrm{O}+1 / 4 \mathrm{NAD}^{+} \rightarrow$ Oxaloacetate $_{\text {mit }}+1 / 4 \mathrm{NADH}_{\text {mit }}+1 / 4 \mathrm{H}^{+}$

21. Acetate $+1 / 2 \mathrm{CoA}+\mathrm{ATP} \rightarrow$ Acetyl$\mathrm{CoA}+\mathrm{ADP}+\mathrm{P}_{\mathrm{i}}$

22. Isocitrate $+1 / 6 \mathrm{NADP}^{+} \rightarrow 5 / 62$-Oxoglutarate + $1 / 6 \mathrm{CO}_{2}+1 / 6 \mathrm{NADPH}_{\text {mit }}$

23. $3 / 4$ Pyruvate $+1 / 4 \mathrm{CO}_{2}+1 / 4 \mathrm{H}_{2} \mathrm{O}+1 / 4 \mathrm{ATP} \rightarrow$ Oxaloacetate $_{\text {cyt }}+1 / 4 \mathrm{ADP}+1 / 4 \mathrm{P}_{\mathrm{i}}+1 / 4 \mathrm{H}^{+}$

24. Glucose-6-P $+1 / 6 \mathrm{ATP} \rightarrow$ Carbohydrate + $1 / 6 \mathrm{ADP}+1 / 3 \mathrm{P}_{\mathbf{i}}$

25. 2-Oxoglutarate $+1 / 5 \mathrm{NH}_{4}^{+}+1 / 5 \mathrm{NADPH}_{\mathrm{cyt}}+$ $1 / 5 \mathrm{H}^{+} \rightarrow$ Glutamate $+1 / 5 \mathrm{H}_{2} \mathrm{O}+1 / 5 \mathrm{NADP}^{+}$

26. Glutamate $+1 / 5 \mathrm{NH}_{4}^{+}+1 / 5 \mathrm{ATP} \rightarrow$ Glutamine $+1 / 5 \mathrm{ADP}+1 / 5 \mathrm{P}_{\mathbf{i}}+1 / 5 \mathrm{H}^{+}$

27. $4 / 9$ Oxaloacetate ${ }_{\mathrm{cyt}}+5 / 9$ Glutamate $\rightarrow$ 4/9Aspartate $+5 / 92$-Oxoglutarate

28. $3 / 83-\mathrm{P}-$ Glycerate $+5 / 8$ Glutamate $+1 / 8 \mathrm{NAD}^{+} \rightarrow$ $3 / 8$ Serine $+5 / 82$-Oxoglutarate $+1 / 8 \mathrm{P}_{1}+$ $1 / 8 \mathrm{NADH}_{\mathrm{cyt}}$

29. $\mathbf{N H}_{4}^{+}(\mathrm{ex})+\mathrm{ATP} \rightarrow \mathrm{NH}_{4}^{+}$(int $)+\mathrm{ADP}+\mathrm{P}_{\mathrm{i}}$

30. 5/23Ribose-5-P $+10 / 23$ Glutamine $+3 / 23$ Serine + $4 / 23$ Aspartate $+1 / 23 \mathrm{CO}_{2}+1 / 23 \mathrm{H}_{2} \mathrm{O}+$ $6 / 23 \mathrm{ATP}+1 / 23 \mathrm{NADP}_{\text {cyt }}{ }^{+} \rightarrow$ 9/235-AICAR + 10/23Glutamate + 4/23Fumarate +1/23NADPH $\mathrm{Nyt}_{\text {ct }}+$ $1 / 23 \mathrm{H}^{+}+6 / 23 \mathrm{ADP}+6 / 23 \mathrm{P}_{\mathrm{i}}$

31. 0.45795-AICAR +0.4371Glutamine + $0.0842 \mathrm{Methyl}^{-\mathrm{FH}_{4}+0.3313 \text { Aspartate }+}$ 0.2544Ribose-5-P + 0.4625ATP + $0 \cdot 0509 \mathrm{NADPH}_{\text {cyt }}+0 \cdot 3301 \mathrm{H}_{2} \mathrm{O}+0 \cdot 1540 \mathrm{NAD}^{+} \rightarrow$ DNA + 0.4371Glutamate + 0.1278 Fumarate + $0.1540 \mathrm{NADH}_{\text {cyt }}+0.0509 \mathrm{NADP}^{+}+0.5166 \mathrm{H}^{+}+$ $0.4625 \mathrm{ADP}+0.4625 \mathrm{P}_{\mathrm{i}}$
32. 0.51125-AICAR +0.5271Glutamine + 0.0568 Methyl- $\mathrm{FH}_{4}+0.2993$ Aspartate + $0 \cdot 2400$ Ribose-5-P + 0.4890ATP $+0 \cdot 3427 \mathrm{H}_{2} \mathrm{O}+$ $0 \cdot 0568 \mathrm{NADP}^{+}+0 \cdot 1348 \mathrm{NAD}^{+} \rightarrow \mathrm{RNA}+0.5271$

Glutamate $+0 \cdot 1073$ Fumarate $+0 \cdot 1348 \mathrm{NADH}_{\text {cyt }}+$ $0.0568 \mathrm{NADPH}_{\text {cyt }}+0.7080 \mathrm{H}^{+}+0.4890 \mathrm{ADP}+$ $0.4890 \mathrm{P}_{\mathrm{i}}$

33. 0-0404Ribose-5-P+0.6090Glutamate + $0 \cdot 2078$ Glutamine +0.2153 Aspartate + $0 \cdot 3380$ Pyruvate $+0 \cdot 1182$ Serine $+0 \cdot 0623$ Erythrose4-P + 0.0935Phosphoenolpyruvate + 1.0396ATP + $0.0495 \mathrm{NADPH}_{\text {mit }}+0.0742 \mathrm{NAD}^{+}{ }_{\text {mit }}+$ $0.0017 \mathrm{NADH}_{\text {cyt }}+0 \cdot 1084 \mathrm{NADPH}_{\text {cyt }}+0.0053 \mathrm{SO}_{4}^{2-}$ $+0.7685 \mathrm{H}_{2} \mathrm{O} \rightarrow$ Protein $+0.49272-$

Oxoglutarate +0.0413 Fumarate +0.0117 Glyceraldehyde-3-P $+0 \cdot 1054 \mathrm{CO}_{2}+$ $0.0100 \mathrm{NH}_{4}^{+}+0.0165 \mathrm{Methyl}^{-\mathrm{FH}_{4}+}$ $0.0742 \mathrm{NADH}_{\text {mit }}+0.01885-\mathrm{AICAR}+1 \cdot 0617 \mathrm{H}^{+}+$ $0.0495 \mathrm{NADP}^{+}{ }_{\text {mit }}+0.0017 \mathrm{NAD}^{+}{ }_{\text {cyt }}+$ $0 \cdot 1084 \mathrm{NADP}^{+}{ }_{\text {cyt }}+1 \cdot 0396 \mathrm{ADP}+1 \cdot 0396 \mathrm{P}_{\mathrm{i}}$

34. 0.8326Acetyl-CoA cyt $+0 \cdot 0662$ Glycerol-3$\mathbf{P}+0 \cdot 1012$ Serine $+0 \cdot 4000 \mathrm{ATP}+$ $0 \cdot 7111 \mathrm{NADPH}_{\text {cyt }}+0.0259 \mathrm{H}^{+} \rightarrow$ Lipid + $0.0258 \mathrm{H}_{2} \mathrm{O}+0.4000 \mathrm{ADP}+0.4000 \mathrm{P}_{\mathrm{i}}+0.4163 \mathrm{CoA}$ 35. ATP $\rightarrow$ 'Maintenance'

36. Oxaloacetate $_{\text {cyt }}+1 / 4$ ATP $\rightarrow$ Oxaloacetate $_{\text {mit }}+1$ $/ 4 \mathrm{ADP}+1 / 4 \mathrm{P}_{\mathrm{i}}+1 / 4 \mathrm{H}^{+}$

37. Acetaldehyde $+1 / 2 \mathrm{NADH}_{\text {mit }}+1 / 2 \mathrm{H}^{+} \rightarrow$ Ethanol $+1 / 2 \mathrm{NAD}^{+}$

Received 13 May 1996; revised 23 July 1996; accepted 23 August 1996. 